Article

\title{
Sustainable Urban External Service Function Development for Building the International Megalopolis in the Pearl River Delta, China
}

\section{Meng Wang ${ }^{1,2,3, *}$, Yaoqiu Kuang ${ }^{1,2, \dagger}$ and Ningsheng Huang ${ }^{1, \dagger}$}

1 Sustainable Development Research Center, Guangzhou Institute of Geochemistry, Chinese Academy of Sciences, Guangzhou 510640, China; E-Mails: yaoqiuk@gig.ac.cn (Y.K.); nshuang@gzb.ac.cn (N.H.)

2 Key Laboratory of Marginal Sea Geology, Chinese Academy of Sciences, Guangzhou 510640, China

3 University of Chinese Academy of Sciences, Beijing 100049, China

$\dagger$ These authors contributed equally to this work.

* Author to whom correspondence should be addressed; E-Mail: mengw@gig.ac.cn; Tel./Fax: +86-20-8529-0476.

Academic Editor: Marc A. Rosen

Received: 24 July 2015 / Accepted: 18 September 2015 / Published: 24 September 2015

\begin{abstract}
This study is about the urban economic service function characteristics and the regional economic contact from the perspectives of region and industries. This paper analyzes the location quotient (LQ), urban external function capability (UEFC), and the characteristics and distribution of urban economic flow intensity (UEFI) of cities in the Pearl River Delta (PRD) region of Guangdong Province, China. Results show: (1) the proportion of the UEFI of Guangzhou and Shenzhen in the PRD region decreased while the one of Foshan and Dongguan increased from 2005 to 2013; (2) the UEFI of Foshan gained the largest increase (532\%) and Zhuhai showed the smallest increase (76\%) from 2005 to 2013; (3) LQs of manufacturing in all cities were greater than one, indicating the overall external service capability of this sector was strong in the PRD region; (4) the numbers of cities whose LQs of tertiary sectors were greater than one reduced from 2005 to 2013, reflecting the urban external service capabilities of the tertiary sectors tended to be concentrated to fewer cities.
\end{abstract}

Keywords: external service functions; employment structure; urban economic flow; urban agglomeration 


\section{Introduction}

Cities and regions have gained increasing attention in the world [1-8]. Urban development cannot separate itself from regional natural and socio-economic conditions to develop in isolation. Core city and its surrounding cities in a region should cooperate with each other by reasonable division of labor to enhance regional comprehensive competitiveness in a metropolitan area. Stronger development driving force of major cities can promote regional integration at a higher level. Agglomeration can give rise to powerful and measurable economic synergies [9-20].

The link between the evolution of regional economy and the patterns of geographical competition and cooperation has been examined in previous study [21-25].

Regional coordinated planning and policy-making is needed to promote regional social and economic integration [26-29].

Industrial ecology concerns the flows of materials and energy that comprise the industrial ecosystem, and the scientific, technical, economic, political, social, and cultural issues related to those flows [30-34].

Urban flow refers to the frequent bidirectional or multidirectional spatial flow of population, goods, information, funds, and technologies in urban agglomeration areas. It is just the increase of urban flow intensity and the common promotion of regional economy that result in the evolution of primary urban agglomerations into senior ones. Urban flow intensity refers to the influencing quantity produced by urban external functions (agglomeration and radiation) in the linkages among all cities in the urban agglomeration area, which is a quantitative index that illustrates the urban contact with surrounding cities. The urban economic flow intensity model was introduced by research group from the Urban Planning and Design Institute of China in 1994 [35]. Since then, more and more regional economic research has used this analysis method as an important evaluation tool. Wang et al. applied this model to analyze the intensity of urban economic flow of urban agglomerations of Central Southern Liaoning, Central Jilin, and Harbin-Daqing-Qiqihar in Northeast China [36]. Liu et al. and Zhang et al. analyzed the economic spatial relations in Beijing-Tianjin-Hebei metropolitan region [37,38]. Zhu et al. analyzed the temporal evolution and spatial characteristics of mid-Zhejiang urban cluster in Eastern China [39]. Liu et al. measured the intensity of urban economic flows of Inner Mongolia in North China in different years [40]. Ke et al. found that external service capabilities of Chinese central cities in the spatio-temporal patterns evolution tended to be more remarkable [41]. Dong et al. calculated and analyzed the intensity of urban economic flow and its structure of the Lanzhou-Xining-Yinchuan Urban Corridor [42]. Han et al. summarized the main features of spatial links among the northeastern cities in China [43].

This study aims to choose the urban agglomerations in the PRD region as a case study to investigate the urban economic flow intensity characteristics and structure by using the UEFI model. In this paper, 15 major external service sectors are selected based on the practical urban functions and major industrial features to analyze and compare the UEFI of the nine cities in the PRD region. The spatial distribution of urban external service capability and the economic contact positions in the PRD region are analyzed in 2005, 2009, and 2013. The paper proceeds as follows: Section 2 describes the data used, and presents the methods to analyze the location quotient, urban external function capacity, and urban economic flow intensity in the PRD. Section 3 reports and discusses the results of the empirical analysis. The paper concludes with a summary of the analysis, some policy recommendations, and some closing remarks. 


\section{Methods}

\subsection{Study Area}

The Pearl River Delta (PRD) is located in southern mainland China adjacent to the South China Sea and is considered one of the country's chief economic regions and manufacturing centers. The study area covers about $54,754 \mathrm{~km}^{2}$ in Guangdong Province, one of the most densely populated provinces with the largest absolute population in China. The PRD region accounts for $30.5 \%$ of the total land area and $53.7 \%$ of the total permanent population of Guangdong Province. The PRD region is building a world-class megalopolis area, and if the cities work together, they can create a new form that will increase economic opportunity and global competitiveness for each individual city and for the region as a whole. A megalopolis can be defined as a large metropolitan area that includes several cities that can provide the outside world with comprehensive external service functions, which could have more than one growth poles and radiation sources in the area to drive its social and economic development.

Priority has been given to develop modern service industry, advanced manufacturing, and high-tech industry as Guangdong Provincial Government has been committed to the construction of advanced modern industry system to achieve the aggregation of industry development and fulfill the high-end oriented industry competitiveness and accelerate the upgrading of industry structure. Moreover, an open, convenient, and efficient transport system in the PRD region has been improved rapidly. The PRD region is faced with a new round of opportunities to strive to become a world-class urban agglomeration. The regional economic integration and the equalization of basic public service in the PRD metropolitan area will be realized in 2020 in accordance with the plan of regional development.

The PRD region comprises nine cities, namely, Guangzhou, Shenzhen, Foshan, Dongguan, Zhongshan, Zhuhai, Huizhou, Jiangmen, and Zhaoqing, as shown in Figure 1. It is one of the most densely urbanized regions in the world and one of the main hubs of China's economic growth. This region is often considered an emerging megacity. There are three urban agglomerations in PRD region, namely, Guangzhou-Foshan-Zhaoqing (GFZ) urban agglomeration, Shenzhen-Dongguan-Huizhou (SDH) urban agglomeration, and Zhuhai-Zhongshan-Jiangmen (ZZJ) urban agglomeration.

The permanent population of the PRD region was 57.15 million persons in 2013. There were 12.93 million people in Guangzhou and 10.63 million people in Shenzhen in 2013. The population clustering condition and the urbanization level could be clearly identified from Figure 2.

As shown in Table 1, Shenzhen-Dongguan-Huizhou urban agglomeration had the highest value in population density, GDP proportion of tertiary industry, per capita disposable income of urban households and amount of foreign capital actually utilized in the PRD in 2013.

As shown in Figure 3, Guangzhou, Shenzhen, and Foshan obtained 444.73 billion RMB, 249.02 billion RMB, and 237.56 billion RMB for investment on fixed assets (IFA) in 2013, respectively. The PRD also attracted a large amount of foreign direct investment (see Figure 4). The IFA comes from state and local budget, domestic loans, foreign investment, self-raising fund and other fund sources, and the investment had been used for construction and installation, purchase of equipment and instruments, and others. 
The GFZ urban cluster attracted the largest amount of investment in fixed assets of manufacturing and tertiary industry in recent years. Foshan centralized most of the IFA of manufacturing, and Guangzhou attracted the largest amount of IFA of tertiary industry (see Figure 5).

The tertiary industry output value in Guangzhou, Shenzhen, and Dongguan accounted for more than $50 \%$ in 2009 and 2013. A steady increase of value-added of tertiary industry had been presented in Figure 6.

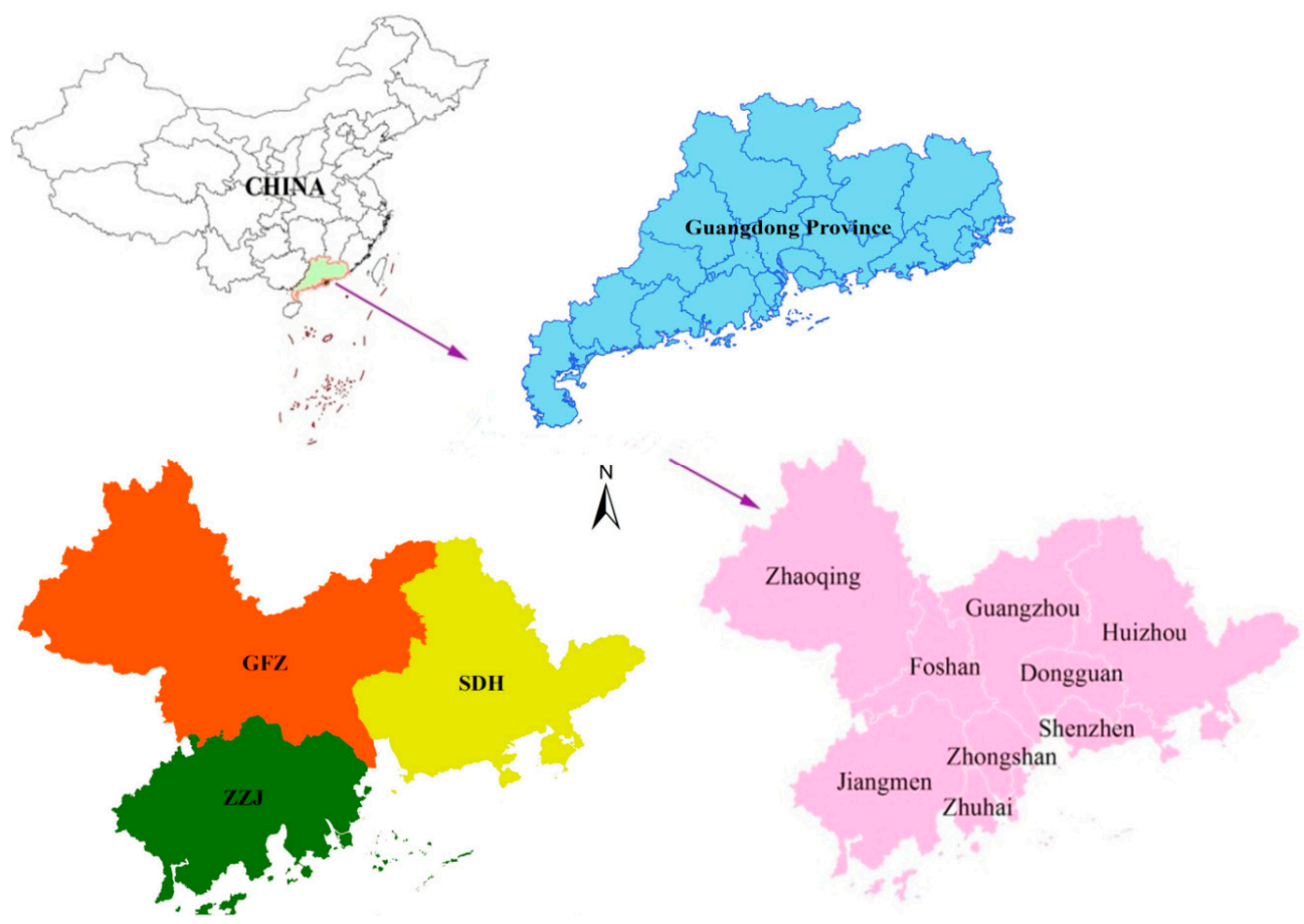

Figure 1. Location of the Pearl River Delta (PRD) region. GFZ is short for GuangzhouFoshan-Zhaoqing urban cluster; SDH is short for Shenzhen-Dongguan-Huizhou urban cluster; and ZZJ is short for Zhuhai-Zhongshan-Jiangmen urban cluster.

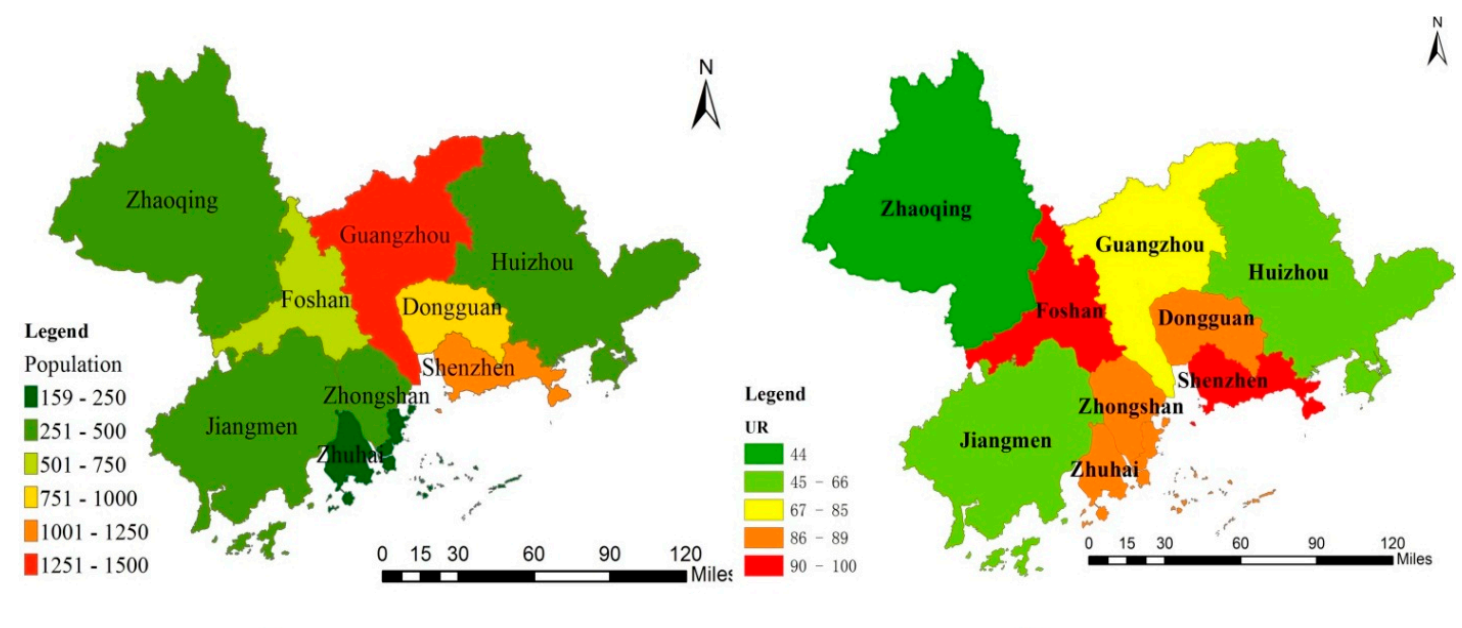

(a)

(b)

Figure 2. (a) The permanent population of cities in PRD Region in 2013 (10,000 persons); and (b) the proportion of urban population to permanent population of cities in PRD region in 2013 (percent) [44]. 
Table 1. Overview of Socio-economic Development of Three Urban Agglomerations in PRD Region in 2013 [44].

\begin{tabular}{cccccc}
\hline $\begin{array}{c}\text { Urban } \\
\text { Agglomerations }\end{array}$ & $\begin{array}{c}\text { Land } \\
\text { Area } \\
\text { (sq.km) }\end{array}$ & $\begin{array}{c}\text { Population } \\
\text { Density } \\
\text { (persons/sq.km) }\end{array}$ & $\begin{array}{c}\text { GDP Proportion } \\
\text { of Tertiary } \\
\text { Industry (\%) }\end{array}$ & $\begin{array}{c}\text { Per Capita } \\
\text { Disposable } \\
\text { Income of Urban } \\
\text { Households } \\
\text { (Yuan) }\end{array}$ & $\begin{array}{c}\text { Amount of Foreign } \\
\text { Capital Actually } \\
\text { Utilized } \\
\text { (USD 10000) }\end{array}$ \\
\hline $\begin{array}{c}\text { Guangzhou- } \\
\text { Foshan-Zhaoqing } \\
\text { Shenzhen- }\end{array}$ & 26,123 & 804.34 & 45.75 & $34,672.22$ & 856,583 \\
$\begin{array}{c}\text { Dongguan-Huizhou } \\
\text { Zhuhai-Zhongshan- } \\
\text { Jiangmen }\end{array}$ & 15,800 & 875.14 & 49.1 & $41,413.03$ & $1,123,981$ \\
\hline
\end{tabular}

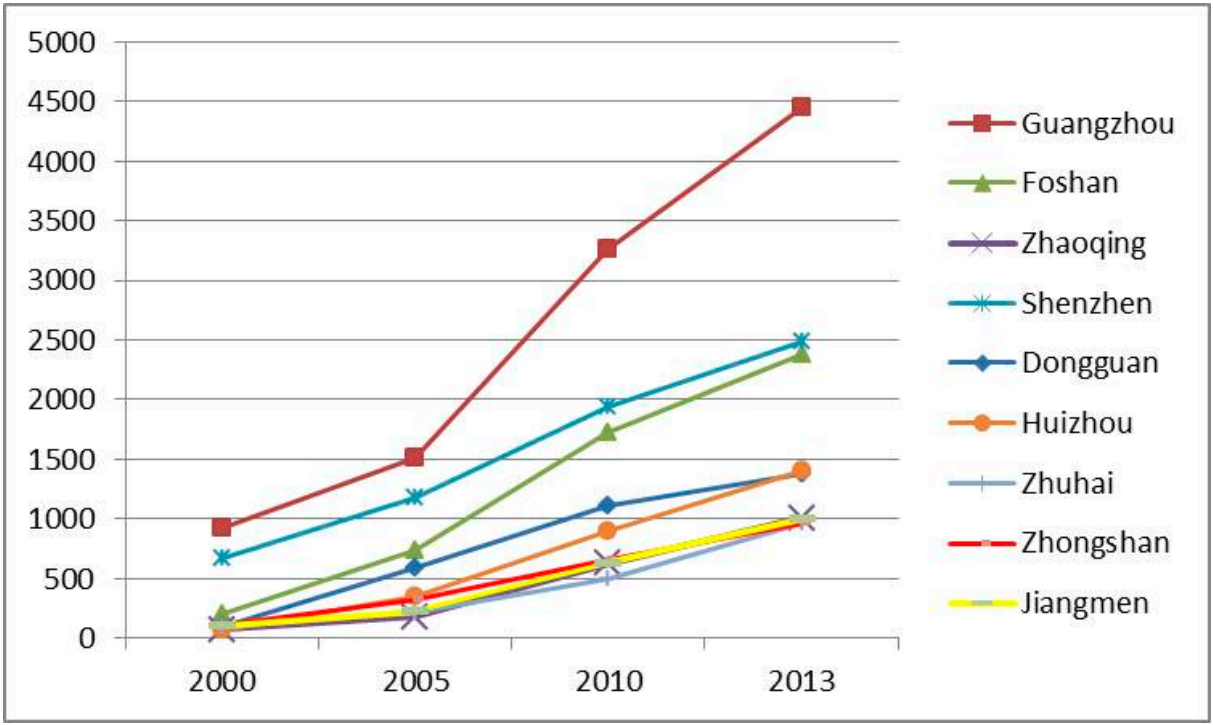

Figure 3. Trends of the investment on fixed assets of the nine cities in the PRD (2000-2013) [44].

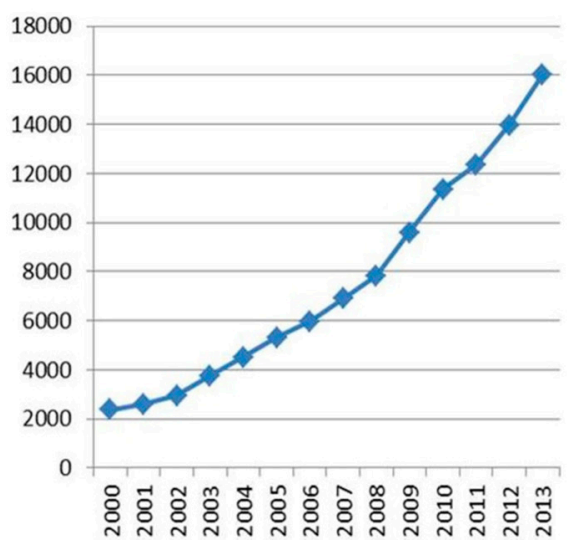

(a)

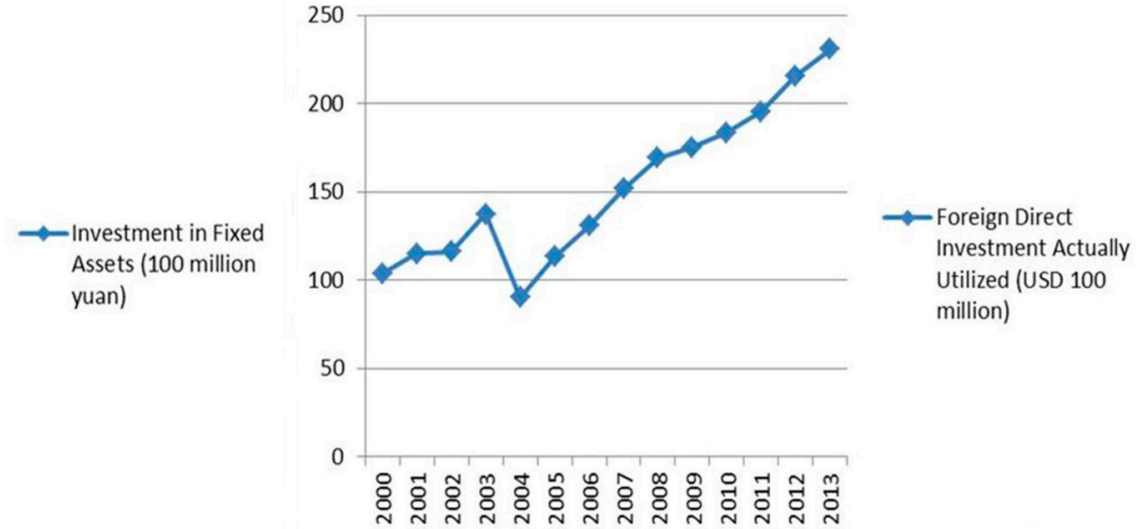

(b)

Figure 4. Trends of investment to the PRD from home and abroad. (a) Investment in fixed assets in the PRD (2000 to 2013); (b) Foreign direct investment actually utilized in the PRD (2000 to 2013) [44]. 


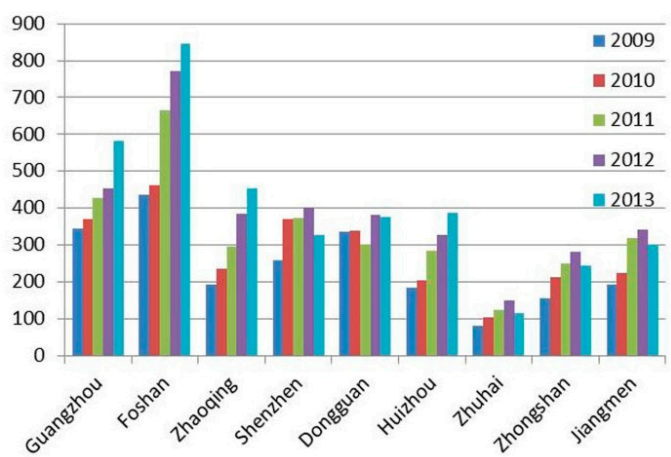

(a)

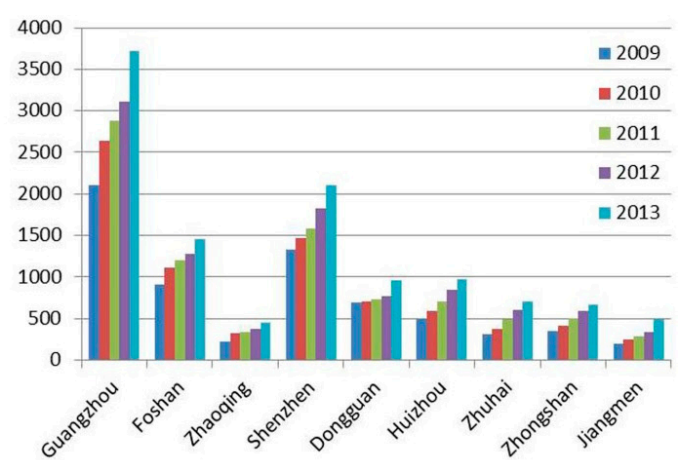

(b)

Figure 5. (a) Investment in fixed assets of manufacturing by city (2009-2013) (100 million yuan); (b) Investment in fixed assets of tertiary industry by city (2009-2013) (100 million yuan) [44].

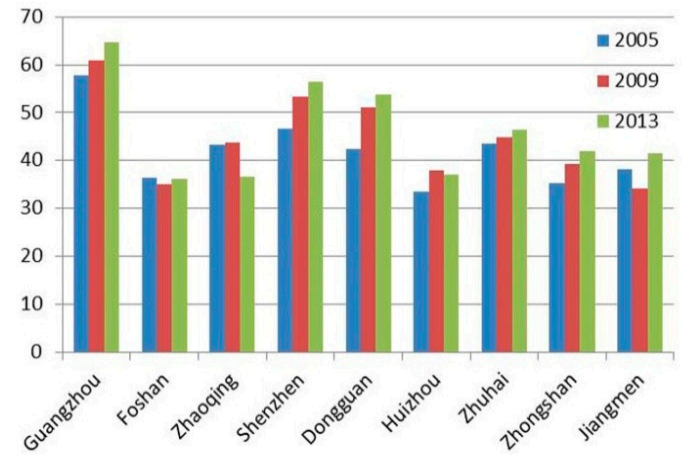

(a)

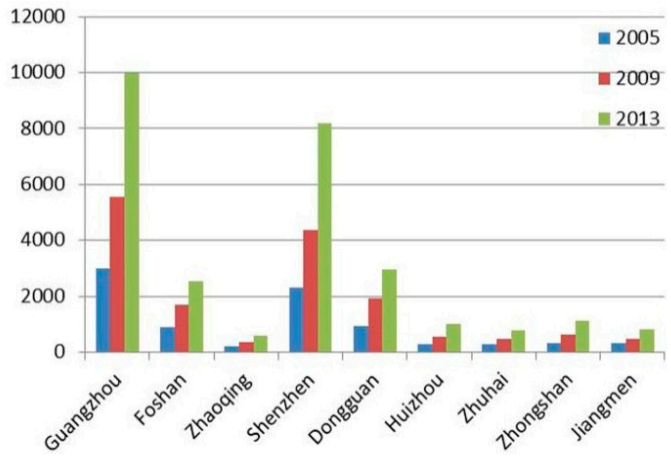

(b)

Figure 6. (a) Proportion of tertiary industry output value in GDP $(2005,2009,2013)(\%)$; (b) Value-added of the tertiary industry by city $(2005,2009,2013)$ (100 million yuan) [44].

As shown in Figure 7, the per capita gross domestic product and per capita tertiary industry gross domestic product of cities increased year by year.

In recent years, a number of important agreements for regional cooperation have been signed jointly to promote the regional integration of cities in the PRD region, as shown in Table 2.

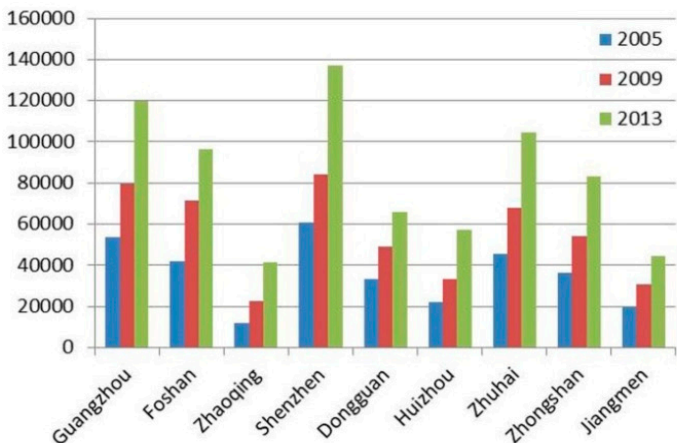

(a)

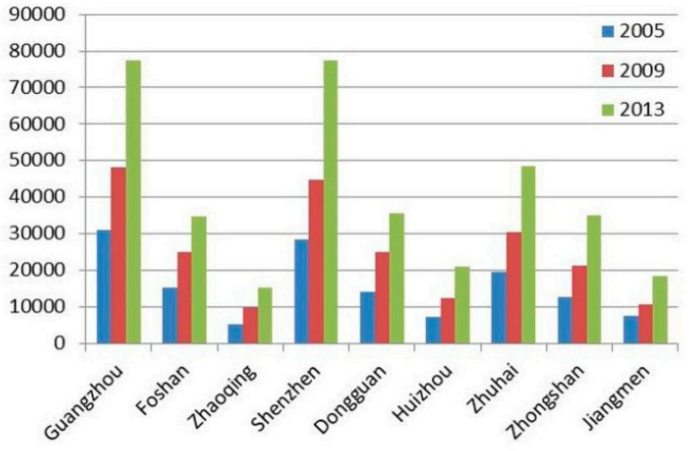

(b)

Figure 7. (a) Per capita gross domestic product by city (2005, 2009, 2013) (yuan); and (b) per capita tertiary industry gross domestic product by city $(2005,2009,2013)$ (yuan) [44]. 
Table 2. Main Agreements for Cooperation Signed Jointly for the Urban Clusters in the PRD region.

\begin{tabular}{|c|c|}
\hline Urban Clusters & Main Policies and Agreements for Cooperation \\
\hline \multirow{10}{*}{$\begin{array}{c}\text { Guangzhou-Foshan- } \\
\text { Zhaoqing (GFZ) }\end{array}$} & GFZ Economic Circle Construction Cooperation Framework Agreement \\
\hline & GFZ Foreign Trade Cooperation Agreement \\
\hline & GFZ Tourism Integration Cooperation Framework Agreement \\
\hline & GFZ Economic Circle Transportation Cooperation Agreement \\
\hline & MOU on Financial Cooperation in GFZ \\
\hline & GFZ Urban and Rural Construction Cooperation Framework Agreement \\
\hline & GFZ Economic Circle Development Planning (2010-2020) \\
\hline & GFZ Industry-university-research and Technological Innovation Cooperation Agreement \\
\hline & GFZ Transport Infrastructure Linking-up Planning (2011-2020) \\
\hline & Overall Development Planning on GFZ (Huaiji) Economic Cooperation Zone (2013-2030) \\
\hline \multirow{5}{*}{$\begin{array}{c}\text { Shenzhen-Dongguan- } \\
\text { Huizhou (SDH) }\end{array}$} & Framework Agreement on Promoting Close Cooperation in Eastern Pearl River Estuary Area \\
\hline & Framework Agreement on Promoting Planning Cooperation in Junction Area of SDH \\
\hline & SDH Industrial Development Cooperation Agreement \\
\hline & Cooperation Agreement on Co-construction of Regional Innovation System in SDH \\
\hline & SDH Transportation Integration Planning \\
\hline \multirow{7}{*}{$\begin{array}{c}\text { Zhuhai-Zhongshan- } \\
\text { Jiangmen (ZZJ) }\end{array}$} & Framework Agreement on Promoting Close Cooperation in ZZJ \\
\hline & ZZJ Tourism Cooperation Agreement \\
\hline & ZZJ Regional Close Educational Cooperation Agreement \\
\hline & ZZJ Regional Normalization Cooperation Agreement \\
\hline & ZZJ Industry-university-research Cooperation Agreement \\
\hline & ZZJ Regional Marine Economic Cooperation Agreement \\
\hline & ZZJ Transport Infrastructure Integration Planning \\
\hline
\end{tabular}

\subsection{Urban Economic External Service Function Assessment}

UEFI is used to present the level of external service capability of each city, referring to the economic flow value a city can output to other cities in regional system of cities.

This study selects 15 index of industries in accordance with their basic functions, including manufacturing, transport, storage and postal services, information transmission, computer services and software, wholesale and retail trade, hotels and catering services, finance, real estate, leasing and business services, scientific research, technical services and geological prospecting, water conservancy, environment and public facilities management, resident services and other services, education, health care, social security and social welfare, culture, sports and recreation, and public administration and social organizations. The existence of a regional labor pool, regional market potential, and changes in investment decisions are key factors in explaining growth in regional absolute specialization levels [45].

Whether $i$ city has its urban external function capacity mainly depends on the location quotient of employees of a sector. The location quotient, also known as the specialization rate, depicts the degree of the relative concentration of a sector in some region, and LQ is calculated as follows [35]:

$$
L Q_{i j}=\frac{Q_{i j} / Q_{i}}{Q_{j} / Q}(\mathrm{i}=1,2, \ldots, \mathrm{n} ; \mathrm{j}=1,2, \ldots, \mathrm{m})
$$


where $Q_{i j}$ and $Q_{i}$ are the number of employees of $j$ industry in $i$ city and the number of employees in $i$ city, respectively, and $Q_{j}$ and $Q$ are the number of employees of $j$ industry in the whole nation and the gross number of employees in the whole nation. The external function capacity of $j$ industry exists on condition that $\mathrm{L} Q_{i j}>1$, because the proportion of employees distributed in $j$ industry in the gross number of employees of $i$ city exceeds the distribution proportion of the nation, that is, $j$ industry of $i$ city can be seen as a specialized sector that can provide the outside with external service compared to the national level. Therefore, the external function capacity of $j$ industry in $i$ city can be expressed as:

$$
E_{i j}=Q_{i j}-Q_{i} \times\left(Q_{j} / Q\right)=Q_{i j}\left(1-1 / L Q_{i j}\right)
$$

Suppose that there are $m$ industries in $i$ city, and $\mathrm{E}_{\mathrm{i}}$ is the overall external function capacity, and can be expressed as follows:

$$
E_{i}=\sum_{j=1}^{m} E_{i j}
$$

The function benefit of $i$ city $\left(N_{i}\right)$ can be calculated as follows:

$$
N_{i}=\frac{G D P_{i}}{Q_{i}}
$$

where $G D P_{i}$ is the gross domestic production of $i$ city.

The urban economic flow intensity of $i$ city $\left(F_{i}\right)$ can be calculated as follows:

$$
F_{i}=N_{i} \times E_{i}=\left(\frac{G D P_{i}}{Q_{i}}\right) \times E_{i}
$$

\subsection{Data Sources}

The data on the numbers of employees of manufacturing, transport, storage and postal services, information transmission, computer services and software, wholesale and retail trade, hotels and catering services, finance, real estate, leasing and business services, scientific research, technical services and geological prospecting, water conservancy, environment and public facilities management, resident services and other services, education, health care, social security and social welfare, culture, sports and recreation, public administration and social organizations are collected from China City Statistical Yearbook (2006, 2010, 2012, 2014) [46]. Moreover, the data on social and economic development such as land area, population, GDP, investment on fixed assets, FDI, etc. are from Guangdong Statistical Yearbook 2014 [44].

\section{Results and Discussion}

\subsection{Location Quotient and Urban Economic External Service Function}

3.1.1. Location Quotient of Major External Service Sectors of cities in PRD in 2005, 2009, 2013

On the one hand, the LQ of manufacturing were all greater than 1 in 2005, 2009, and 2013, which could show the strong human capital agglomeration ability in manufacturing in the PRD (see Tables 3-5). 
On the other hand, the specialization level of service subsectors in cities indicated the differentiation of the urban external service functions.

Table 3. Location quotient of major external Sectors in 2005.

\begin{tabular}{|c|c|c|c|c|c|c|c|c|c|}
\hline Sectors & Guangzhou & Foshan & Zhaoqing & Shenzhen & Dongguan & Huizhou & Zhuhai & Zhongshan & Jiangmen \\
\hline Manufacturing & 1.23 & 1.52 & 1.27 & 1.59 & 1.27 & 2.42 & 2.32 & 2.03 & 1.59 \\
\hline $\begin{array}{c}\text { Transport, } \\
\text { storage and } \\
\text { postal services }\end{array}$ & 1.97 & 0.70 & 0.69 & 1.23 & 1.00 & 0.33 & 0.56 & 0.58 & 0.58 \\
\hline $\begin{array}{l}\text { Information } \\
\text { transmission, } \\
\text { computer } \\
\text { services }\end{array}$ & 1.67 & 1.32 & 1.32 & 1.56 & 1.05 & 0.51 & 1.09 & 0.96 & 0.70 \\
\hline $\begin{array}{c}\text { Wholesale and } \\
\text { retail trade }\end{array}$ & 0.98 & 0.60 & 0.58 & 1.05 & 0.47 & 0.23 & 0.51 & 0.29 & 0.41 \\
\hline $\begin{array}{c}\text { Hotels and } \\
\text { catering services }\end{array}$ & 2.41 & 1.10 & 1.14 & 1.71 & 0.28 & 0.50 & 1.30 & 1.08 & 0.93 \\
\hline Finance & 1.00 & 2.03 & 0.97 & 1.02 & 3.04 & 0.52 & 0.60 & 1.51 & 1.24 \\
\hline Real estate & 1.99 & 0.87 & 0.78 & 4.12 & 0.18 & 0.89 & 1.37 & 0.46 & 0.49 \\
\hline $\begin{array}{c}\text { Leasing and } \\
\text { business } \\
\text { services }\end{array}$ & 1.61 & 1.01 & 0.60 & 2.24 & 0.38 & 0.50 & 0.72 & 0.61 & 0.54 \\
\hline $\begin{array}{l}\text { Scientific } \\
\text { research, } \\
\text { technical } \\
\text { services }\end{array}$ & 1.36 & 0.42 & 0.54 & 0.88 & 0.42 & 0.33 & 0.23 & 0.67 & 0.43 \\
\hline $\begin{array}{c}\text { Water } \\
\text { conservancy, } \\
\text { environment } \\
\text { management }\end{array}$ & 0.89 & 0.79 & 1.03 & 0.63 & 0.24 & 0.62 & 0.85 & 0.60 & 1.17 \\
\hline $\begin{array}{c}\text { Resident } \\
\text { services and } \\
\text { other services }\end{array}$ & 1.10 & 0.17 & 0.21 & 0.49 & 0.05 & 0.07 & 0.49 & 0.28 & 0.34 \\
\hline Education & 0.63 & 0.87 & 1.30 & 0.26 & 0.96 & 0.49 & 0.27 & 0.69 & 0.99 \\
\hline $\begin{array}{c}\text { Health, social } \\
\text { security and } \\
\text { social welfare }\end{array}$ & 1.00 & 1.10 & 1.56 & 0.54 & 2.32 & 0.53 & 0.41 & 1.00 & 1.19 \\
\hline $\begin{array}{l}\text { Culture, sports } \\
\text { and recreation }\end{array}$ & 1.38 & 0.54 & 0.99 & 0.74 & 0.67 & 0.45 & 0.76 & 0.98 & 0.45 \\
\hline $\begin{array}{c}\text { Public } \\
\text { administration } \\
\text { and social } \\
\text { organizations }\end{array}$ & 0.62 & 0.81 & 1.27 & 0.52 & 1.49 & 0.58 & 0.52 & 0.61 & 0.97 \\
\hline
\end{tabular}


Table 4. Location quotient of major external Sectors in 2009.

\begin{tabular}{|c|c|c|c|c|c|c|c|c|c|}
\hline Sectors & Guangzhou & Foshan & Zhaoqing & Shenzhen & Dongguan & Huizhou & Zhuhai & Zhongshan & Jiangmen \\
\hline Manufacturing & 1.25 & 1.62 & 1.32 & 1.66 & 1.30 & 2.48 & 2.27 & 2.05 & 1.71 \\
\hline $\begin{array}{c}\text { Transport, } \\
\text { storage and } \\
\text { postal services }\end{array}$ & 2.10 & 0.65 & 0.69 & 1.37 & 0.66 & 0.34 & 0.54 & 0.73 & 0.55 \\
\hline $\begin{array}{c}\text { Information } \\
\text { transmission, } \\
\text { computer } \\
\text { services }\end{array}$ & 1.52 & 1.55 & 0.96 & 1.42 & 0.79 & 0.29 & 1.00 & 0.70 & 0.74 \\
\hline $\begin{array}{c}\text { Wholesale and } \\
\text { retail trade }\end{array}$ & 1.18 & 0.53 & 0.58 & 1.33 & 0.62 & 0.33 & 0.72 & 0.22 & 0.47 \\
\hline $\begin{array}{c}\text { Hotels and } \\
\text { catering services }\end{array}$ & 2.42 & 1.14 & 1.11 & 1.80 & 0.19 & 0.53 & 1.15 & 0.82 & 1.18 \\
\hline Finance & 0.88 & 1.35 & 0.81 & 1.09 & 2.40 & 0.55 & 0.76 & 1.34 & 1.25 \\
\hline Real estate & 1.96 & 0.70 & 0.52 & 3.44 & 0.14 & 0.71 & 1.46 & 0.76 & 0.43 \\
\hline $\begin{array}{c}\text { Leasing and } \\
\text { business } \\
\text { services }\end{array}$ & 1.76 & 0.48 & 0.58 & 2.11 & 0.44 & 0.40 & 0.70 & 0.80 & 0.32 \\
\hline $\begin{array}{l}\text { Scientific } \\
\text { research, } \\
\text { technical } \\
\text { services }\end{array}$ & 1.26 & 0.42 & 0.45 & 0.89 & 0.39 & 0.26 & 0.29 & 0.33 & 0.28 \\
\hline $\begin{array}{c}\text { Water } \\
\text { conservancy, } \\
\text { environment } \\
\text { management }\end{array}$ & 0.77 & 0.63 & 1.21 & 0.62 & 0.16 & 0.55 & 0.81 & 0.26 & 0.92 \\
\hline $\begin{array}{c}\text { Resident } \\
\text { services and } \\
\text { other services }\end{array}$ & 2.54 & 0.41 & 0.31 & 1.59 & 0.09 & 0.35 & 0.53 & 0.16 & 0.95 \\
\hline Education & 0.62 & 1.01 & 1.45 & 0.26 & 0.95 & 0.44 & 0.31 & 0.77 & 0.89 \\
\hline $\begin{array}{c}\text { Health, social } \\
\text { security and } \\
\text { social welfare }\end{array}$ & 0.96 & 1.28 & 1.48 & 0.47 & 2.35 & 0.51 & 0.37 & 1.09 & 1.09 \\
\hline $\begin{array}{l}\text { Culture, sports } \\
\text { and recreation }\end{array}$ & 1.45 & 0.33 & 0.91 & 0.75 & 0.82 & 0.40 & 0.66 & 0.80 & 0.38 \\
\hline $\begin{array}{c}\text { Public } \\
\text { administration } \\
\text { and social } \\
\text { organizations }\end{array}$ & 0.61 & 0.87 & 1.23 & 0.47 & 1.64 & 0.62 & 0.46 & 0.75 & 0.89 \\
\hline
\end{tabular}


Table 5. Location quotient of major external sectors in 2013.

\begin{tabular}{|c|c|c|c|c|c|c|c|c|c|}
\hline Sectors & Guangzhou & Foshan & Zhaoqing & Shenzhen & Dongguan & Huizhou & Zhuhai & Zhongshan & Jiangmen \\
\hline Manufacturing & 1.03 & 2.40 & 1.57 & 1.89 & 2.75 & 2.19 & 1.81 & 2.52 & 1.79 \\
\hline $\begin{array}{c}\text { Transport, } \\
\text { storage and } \\
\text { postal services }\end{array}$ & 2.52 & 0.48 & 0.73 & 1.08 & 0.30 & 0.54 & 0.73 & 0.40 & 0.76 \\
\hline $\begin{array}{c}\text { Information } \\
\text { transmission, } \\
\text { computer } \\
\text { services }\end{array}$ & 1.36 & 0.40 & 0.48 & 1.29 & 0.16 & 0.37 & 1.12 & 0.28 & 0.37 \\
\hline $\begin{array}{c}\text { Wholesale and } \\
\text { retail trade }\end{array}$ & 1.59 & 0.59 & 0.63 & 0.99 & 0.47 & 0.60 & 0.75 & 0.61 & 0.72 \\
\hline $\begin{array}{c}\text { Hotels and } \\
\text { catering services }\end{array}$ & 1.47 & 0.60 & 0.70 & 0.93 & 0.74 & 0.44 & 1.23 & 0.75 & 0.99 \\
\hline Finance & 0.82 & 0.58 & 0.82 & 0.81 & 0.40 & 1.00 & 0.72 & 0.54 & 1.25 \\
\hline Real estate & 2.47 & 0.81 & 0.77 & 1.71 & 0.45 & 0.93 & 1.75 & 0.89 & 0.61 \\
\hline $\begin{array}{c}\text { Leasing and } \\
\text { business } \\
\text { services }\end{array}$ & 2.49 & 0.44 & 0.43 & 1.93 & 0.78 & 0.42 & 0.85 & 0.43 & 0.28 \\
\hline $\begin{array}{l}\text { Scientific } \\
\text { research, } \\
\text { technical } \\
\text { services }\end{array}$ & 2.06 & 0.31 & 0.35 & 0.82 & 0.21 & 0.26 & 0.52 & 0.28 & 0.27 \\
\hline $\begin{array}{c}\text { Water } \\
\text { conservancy, } \\
\text { environment } \\
\text { management }\end{array}$ & 1.17 & 0.40 & 0.95 & 0.20 & 0.07 & 0.69 & 0.85 & 0.21 & 0.62 \\
\hline $\begin{array}{c}\text { Resident } \\
\text { services and } \\
\text { other services }\end{array}$ & 0.64 & 0.30 & 0.17 & 0.36 & 0.46 & 0.08 & 0.22 & 0.04 & 0.16 \\
\hline Education & 0.61 & 0.57 & 1.45 & 0.23 & 0.17 & 0.65 & 0.42 & 0.39 & 0.84 \\
\hline $\begin{array}{c}\text { Health, social } \\
\text { security and } \\
\text { social welfare }\end{array}$ & 0.72 & 0.64 & 1.45 & 0.32 & 0.46 & 0.71 & 0.49 & 0.49 & 1.10 \\
\hline $\begin{array}{l}\text { Culture, sports } \\
\text { and recreation }\end{array}$ & 1.41 & 0.27 & 0.60 & 0.61 & 0.39 & 0.59 & 0.60 & 0.35 & 0.45 \\
\hline $\begin{array}{c}\text { Public } \\
\text { administration } \\
\text { and social } \\
\text { organizations }\end{array}$ & 0.60 & 0.38 & 1.32 & 0.39 & 0.26 & 0.84 & 0.56 & 0.33 & 0.92 \\
\hline
\end{tabular}

Table 6 shows in 2013, the PRD accounted for over 85\% of Guangdong's employees of transport, storage and postal services, information transmission, computer services, hotels and catering services, real estate, leasing and business services, scientific research, technical services, resident services and manufacturing. 
Table 6. The Proportion of main external service sectors employees in the total number of employees of the same sectors in Guangdong province in 2013 [44].

\begin{tabular}{|c|c|c|c|c|c|c|c|c|c|c|}
\hline $\begin{array}{c}\text { External Service } \\
\text { Sectors }\end{array}$ & Guangzhou & Foshan & Zhaoqing & Shenzhen & Dongguan & Huizhou & Zhuhai & Zhongshan & Jiangmen & PRD \\
\hline $\begin{array}{l}\text { Transport, storage } \\
\text { and postal services }\end{array}$ & $42 \%$ & $4 \%$ & $2 \%$ & $25 \%$ & $4 \%$ & $2 \%$ & $3 \%$ & $2 \%$ & $2 \%$ & $86 \%$ \\
\hline $\begin{array}{c}\text { Information } \\
\text { transmission, } \\
\text { computer services }\end{array}$ & $28 \%$ & $4 \%$ & $1 \%$ & $38 \%$ & $3 \%$ & $2 \%$ & $5 \%$ & $2 \%$ & $1 \%$ & $85 \%$ \\
\hline $\begin{array}{l}\text { Wholesale and } \\
\text { retail trade }\end{array}$ & $30 \%$ & $6 \%$ & $2 \%$ & $26 \%$ & $7 \%$ & $3 \%$ & $3 \%$ & $3 \%$ & $2 \%$ & $83 \%$ \\
\hline $\begin{array}{c}\text { Hotels and catering } \\
\text { services }\end{array}$ & $28 \%$ & $6 \%$ & $2 \%$ & $25 \%$ & $10 \%$ & $2 \%$ & $5 \%$ & $4 \%$ & $3 \%$ & $85 \%$ \\
\hline Finance & $18 \%$ & $7 \%$ & $2 \%$ & $25 \%$ & $7 \%$ & $6 \%$ & $4 \%$ & $3 \%$ & $5 \%$ & $75 \%$ \\
\hline Real estate & $32 \%$ & $6 \%$ & $1 \%$ & $32 \%$ & $4 \%$ & $3 \%$ & $5 \%$ & $3 \%$ & $1 \%$ & $89 \%$ \\
\hline $\begin{array}{c}\text { Leasing and } \\
\text { business services }\end{array}$ & $35 \%$ & $3 \%$ & $1 \%$ & $38 \%$ & $8 \%$ & $2 \%$ & $3 \%$ & $2 \%$ & $1 \%$ & $92 \%$ \\
\hline $\begin{array}{l}\text { Scientific research, } \\
\text { technical services }\end{array}$ & $47 \%$ & $4 \%$ & $1 \%$ & $27 \%$ & $4 \%$ & $2 \%$ & $3 \%$ & $2 \%$ & $1 \%$ & $90 \%$ \\
\hline $\begin{array}{c}\text { Water } \\
\text { conservancy, } \\
\text { environment } \\
\text { management } \\
\end{array}$ & $31 \%$ & $6 \%$ & $3 \%$ & $8 \%$ & $1 \%$ & $5 \%$ & $5 \%$ & $2 \%$ & $3 \%$ & $64 \%$ \\
\hline $\begin{array}{l}\text { Resident services } \\
\text { and other services }\end{array}$ & $33 \%$ & $8 \%$ & $1 \%$ & $26 \%$ & $18 \%$ & $1 \%$ & $3 \%$ & $1 \%$ & $2 \%$ & $93 \%$ \\
\hline Education & $15 \%$ & $7 \%$ & $4 \%$ & $8 \%$ & $3 \%$ & $4 \%$ & $2 \%$ & $3 \%$ & $4 \%$ & $50 \%$ \\
\hline $\begin{array}{c}\text { Health, social } \\
\text { security and social } \\
\text { welfare }\end{array}$ & $17 \%$ & $8 \%$ & $4 \%$ & $10 \%$ & $8 \%$ & $4 \%$ & $3 \%$ & $3 \%$ & $5 \%$ & $63 \%$ \\
\hline $\begin{array}{c}\text { Culture, sports and } \\
\text { recreation }\end{array}$ & $34 \%$ & $3 \%$ & $2 \%$ & $21 \%$ & $7 \%$ & $4 \%$ & $3 \%$ & $2 \%$ & $2 \%$ & $80 \%$ \\
\hline $\begin{array}{c}\text { Public } \\
\text { administration and } \\
\text { social } \\
\text { organizations }\end{array}$ & $15 \%$ & $5 \%$ & $4 \%$ & $14 \%$ & $5 \%$ & $6 \%$ & $3 \%$ & $2 \%$ & $4 \%$ & $59 \%$ \\
\hline Manufacturing & $10 \%$ & $12 \%$ & $2 \%$ & $25 \%$ & $20 \%$ & $5 \%$ & $4 \%$ & $7 \%$ & $3 \%$ & $87 \%$ \\
\hline
\end{tabular}

3.1.2. Comparative Analysis of the Employment Structure in Major External Service Sectors in Guangzhou and Shenzhen

Compared with Shenzhen, Guangzhou has more employees in sectors such as transport, storage and postal services, wholesale and retail trade, scientific research, technical services and geological prospecting, water conservancy, environment and public facilities management, education, health care, social security and social welfare, culture, sports and recreation, and public administration and social organizations from 2005 to 2013. Particularly, Guangzhou has remarkable advantage in terms of the 
number of employees in transport, storage and postal services sectors, scientific research, technical services and geological prospecting sectors and water conservancy, environment and public facilities management sectors (see Figure 8). However, Shenzhen takes the lead in the number of employees in information transmission, computer services and software, finance, leasing and business services, and manufacturing sectors, as shown in Figure 9.

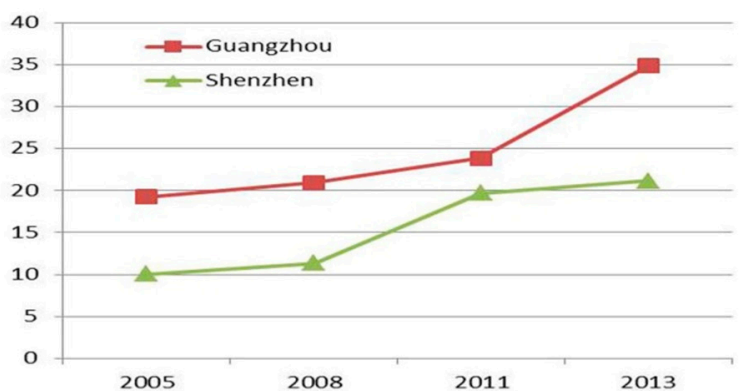

(a)

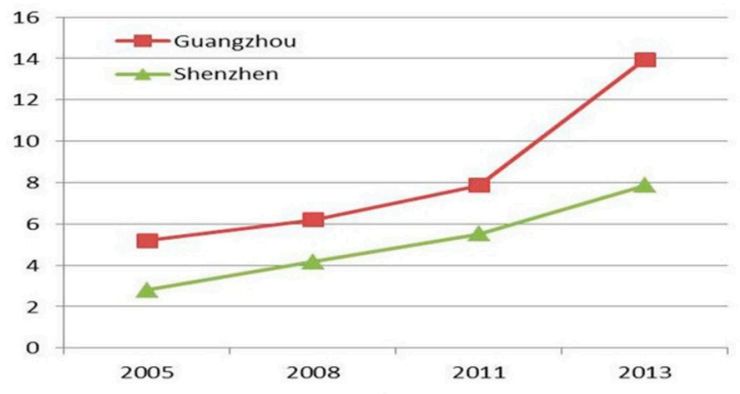

(c)

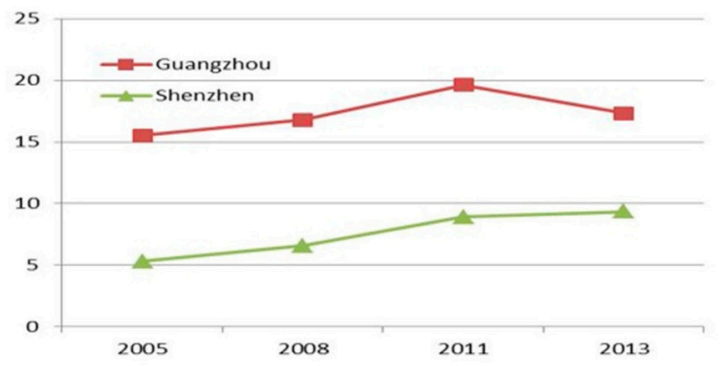

(e)

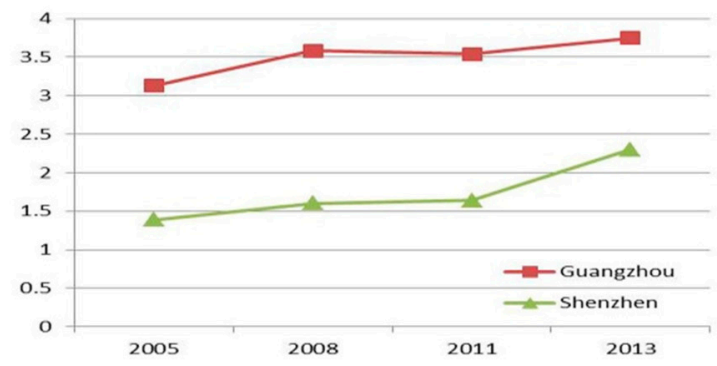

(g)

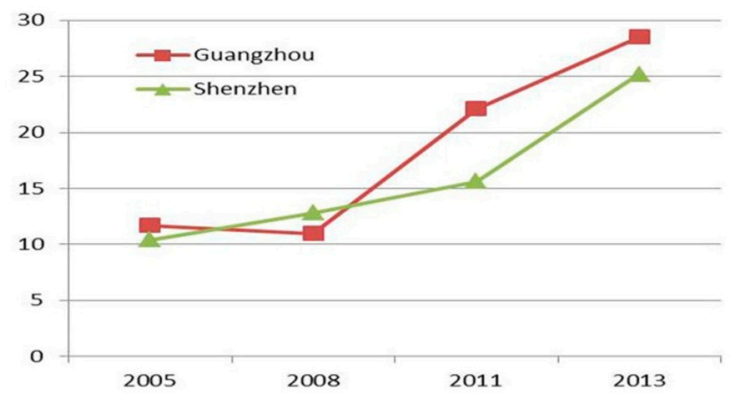

(b)

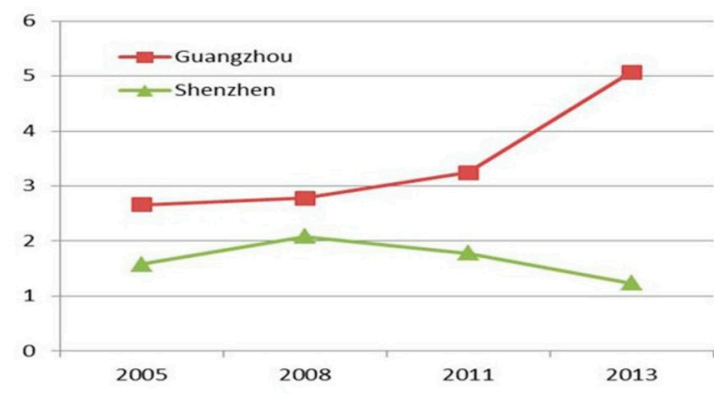

(d)

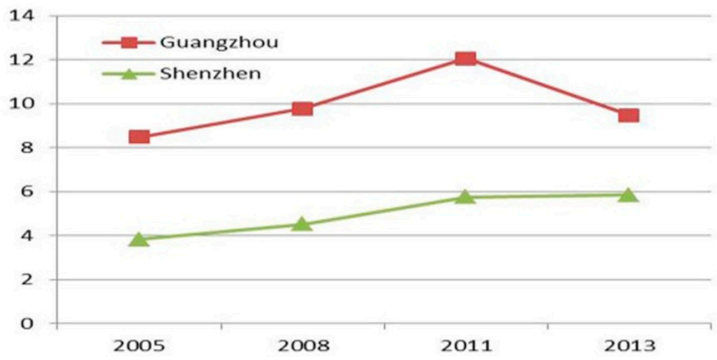

(f)

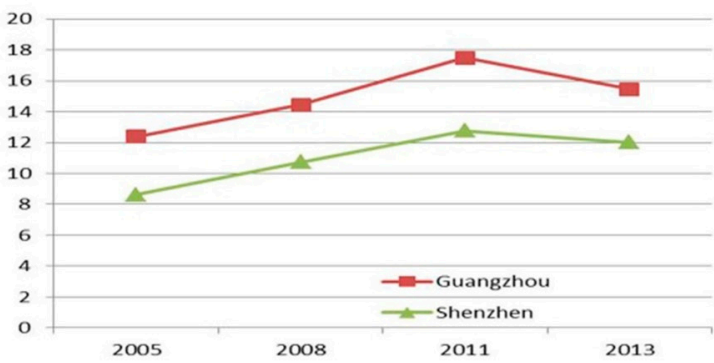

(h)

Figure 8. Change of the number of employees of main external service sectors in Guangzhou and Shenzhen (2005, 2008, 2011, 2013) (10,000 persons). (a) Transport, storage and postal services; (b) wholesale and retail trade; (c) Scientific research, technical services and geological prospecting; (d) Water conservancy, environment and public facilities management; (e) Education; (f) Health care, social security and social welfare; (g) Culture, sports and recreation; and (h) Public administration and social organizations. 


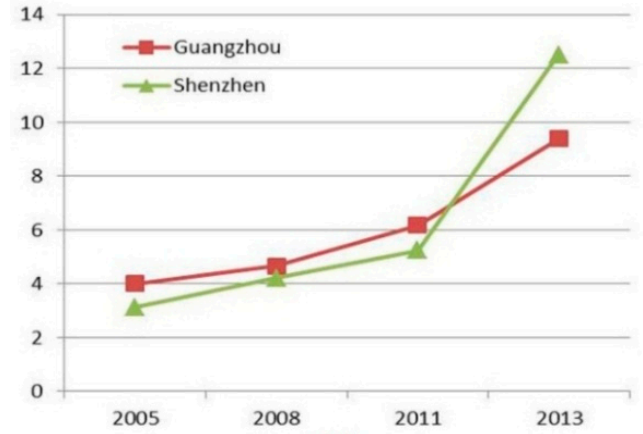

(a)

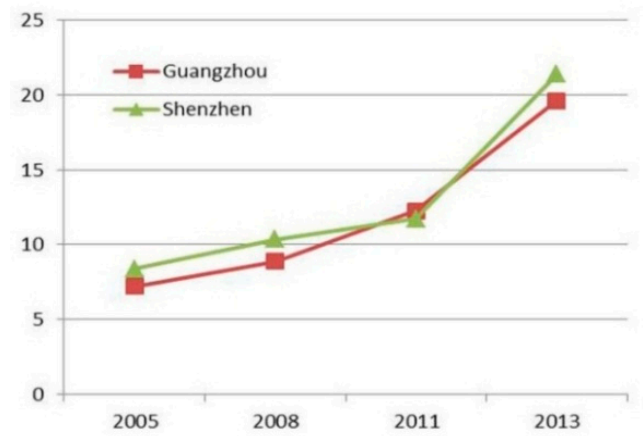

(c)

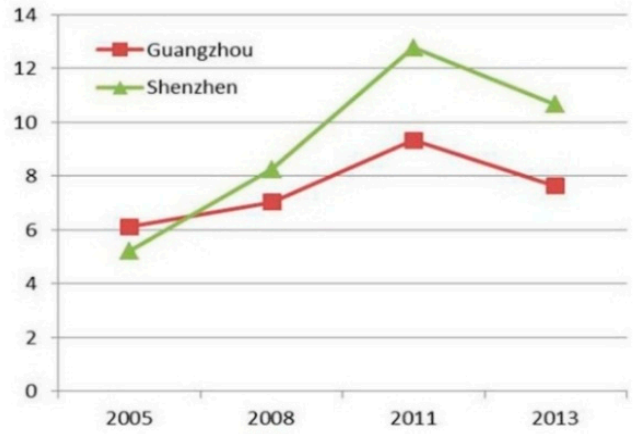

(b)

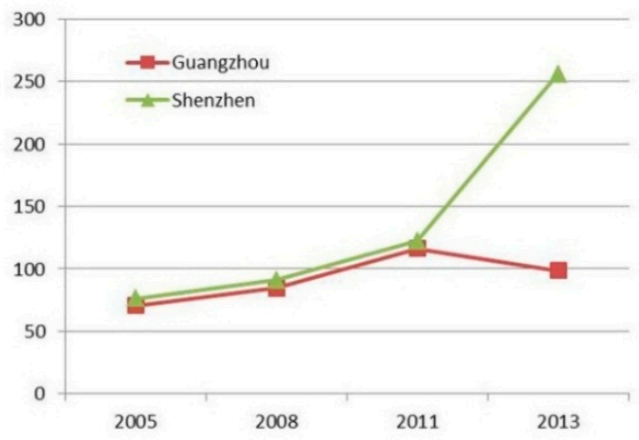

(d)

Figure 9. (a) Information transmission, computer services and software; (b) finance; (c) leasing and business services; and (d) manufacturing.

The gap of employment in sectors such as hotels and catering services, real estate, resident services and other services appears narrowed between Guangzhou and Shenzhen in recent years (see Figure 10).

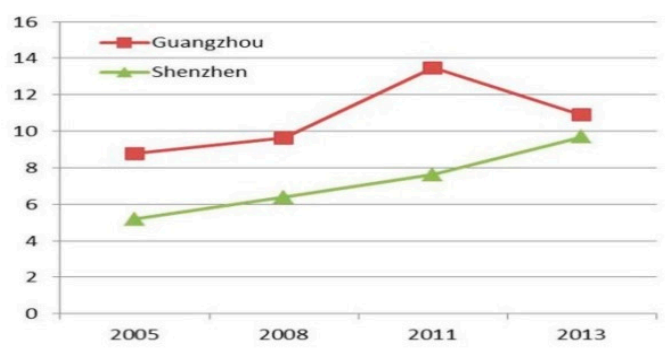

(a)

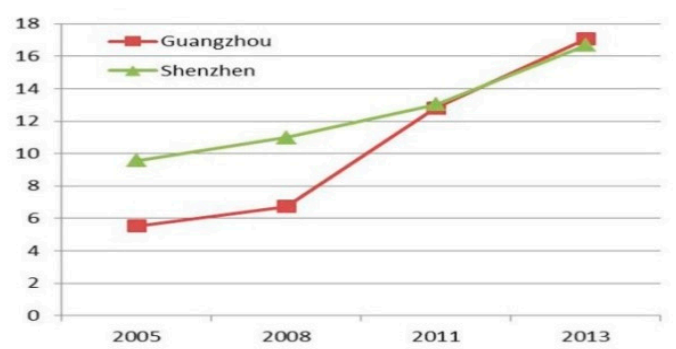

(b)

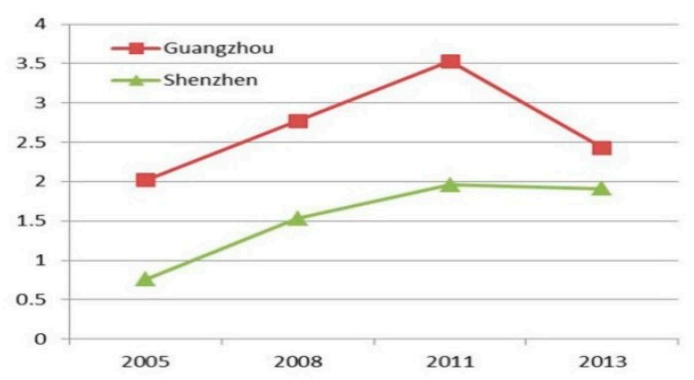

(c)

Figure 10. (a) Hotels and catering services; (b) real Estate; and (c) resident services and other services. 


\subsubsection{Development of Main Emerging Sub-Sectors of the Service Industries}

The rise of the Internet is often associated with the "death of distance" or, at least, the decreasing relevance of geographical distance in the supply of information. The importance of geographical distance-related trade costs is indeed greatly reduced in online trade, compared to offline trade [47]. In the course of transition from the old economy to the new one, e-commerce has eliminated the problem of time and space which, in return, has lowered costs in production processes. Thus, e-commerce has become a dynamic factor in the new economy. Telecommunications and transport links flourished by the globalization created a new way of accessing to the new markets through e-commerce. In a broad sense, e-commerce has been affecting employment patterns, productivity, and industry structure [48].

It is a common view in China that consumers can pick low-priced goods much more easily by shopping online even if the goods may vary in quality. The diversification of shopping choice is the great appeal for shoppers online, as there are a large number of varieties of goods. As a consequence, the economic development of the e-commerce sector is exponential in China.

According to the Twelfth Five-year Plan of E-commerce in Guangdong, Internet penetration reached $55.3 \%$ in Guangdong Province in 2010, and the number of Internet users reached 53.24 million people. $36.2 \%$ of the Internet users shopped online. The trade scale of e-commerce kept increasing to 800 billion RMB. E-commerce has become a significant way of modern commodity circulation.

The concentrated development degree of e-commerce is high in the PRD region. For instance, Guangzhou has been rated the national model city of mobile e-commerce, and Shenzhen has become the first city to establish the national model city of e-commerce in China. A number of e-commerce cluster areas with clusters of leading enterprises have come into being in Guangzhou, Shenzhen, Foshan, and Dongguan.

As a result, the emerging logistics distribution industry (e.g., the express delivery industry) has been one of the e-commerce-propelled industries of the e-commerce service chain. Figure 11 presents the proportion distribution disparity of the express pieces in the PRD region.

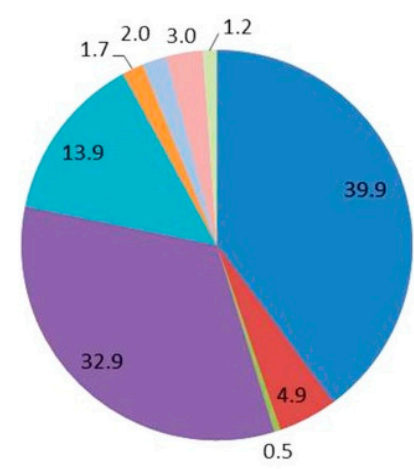

(a)

$$
\begin{aligned}
& \text { = Guangzhou } \\
& \text { = Foshan } \\
& \text { = Zhaoqing } \\
& \text { = Shenzhen } \\
& \text { = Dongguan } \\
& \text { = Huizhou } \\
& \text { = Zhuhai } \\
& \text { = Zhongshan } \\
& \text { = Jiangmen }
\end{aligned}
$$

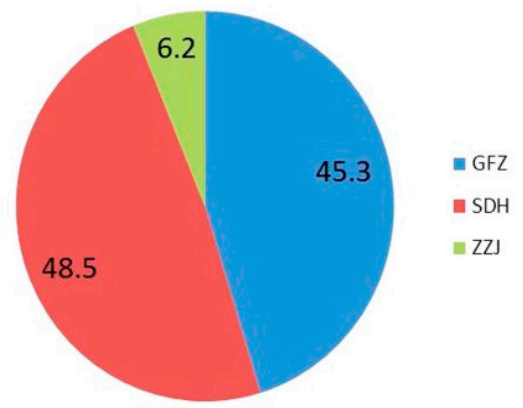

(b)

Figure 11. (a) The proportion of express mail pieces by city in the PRD in 2013; and (b) the proportion of express mail pieces by urban cluster in the PRD in 2013.

Nowadays, there are more and more mobile phone users and Internet service users in the world, and the situation is even more remarkable in the PRD region of China (see Figure 12). As technology 
improves rapidly, consumers can easily gain access to Internet service with computers or mobile phones anywhere and anytime.

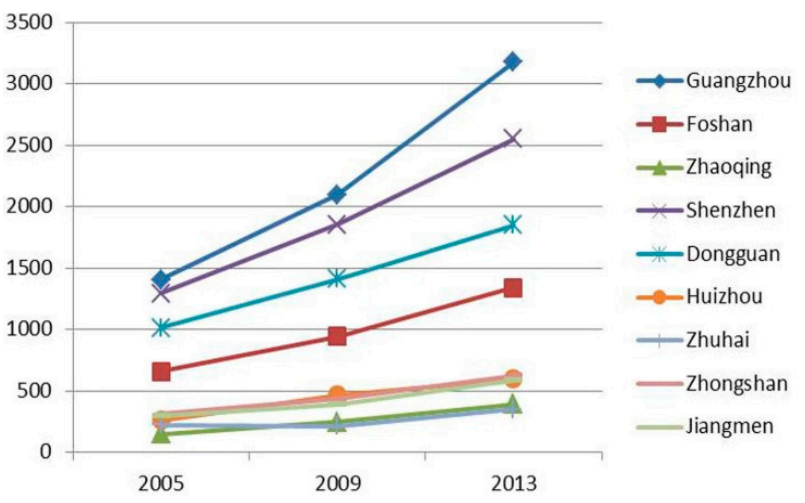

(a)

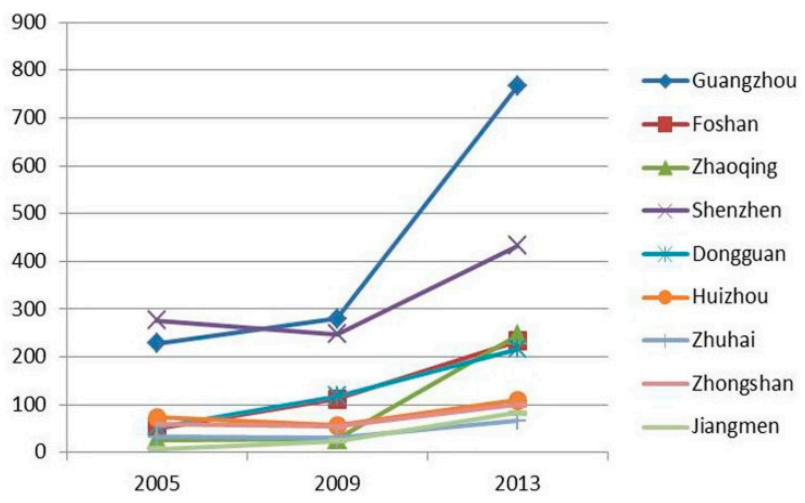

(b)

Figure 12. (a) Number of subscribers of mobile telephones (10,000 households); and (b) number of subscribers of Internet services (10,000 household).

The express mail industry in Guangdong Province kept its rapid growth to achieve 2.068 billion pieces which accounted for $24.4 \%$ of the total business volume in China, and the rate of increase was higher than the national average level [49]. It is worth mentioning that the postal enterprises and express mail companies of Dongguan fulfilled 6.225 billion RMB merely in the first five months of 2015, with year-on-year growth of more than 108.2\% [50]. The postal business volume of Zhongshan achieved 1.146 billion RMB in the first five months of 2015, with year-on-year growth of 51.93\% [51]. The postal business volume of Jiangmen reached 478 million RMB in the first five months of 2015, with year-on-year growth of 53.41\% [52]. Furthermore, the consuming willingness and capability of people in the PRD region are so strong that there will be a clear vision of an optimistic and active economic situation both online and offline in the long run (see Table 7).

Table 7. Per capita disposable income and consumption expenditure of urban households by city in the PRD (2000-2013).

\begin{tabular}{ccccccccccccc}
\hline \multicolumn{10}{c}{ Per Capita Disposable Income and Consumption Expenditure of Urban Households by City } \\
\hline \multicolumn{1}{c}{} & \multicolumn{9}{c}{ Disposable Income (yuan) } & \multicolumn{5}{c}{ Consumption Expenditure (yuan) } \\
\hline & $\mathbf{2 0 0 0}$ & $\mathbf{2 0 0 5}$ & $\mathbf{2 0 1 0}$ & $\mathbf{2 0 1 2}$ & $\mathbf{2 0 1 3}$ & $\mathbf{2 0 0 0}$ & $\mathbf{2 0 0 5}$ & $\mathbf{2 0 1 0}$ & $\mathbf{2 0 1 2}$ & $\mathbf{2 0 1 3}$ \\
\hline Guangzhou & $13,621.83$ & $18,287.24$ & $30,658.49$ & $38,053.52$ & $42,049.14$ & $10,988.99$ & $14,468.24$ & $25,011.61$ & $30,490.44$ & $33,156.829$ \\
Foshan & $11,976.98$ & $17,680.1$ & $27,244.68$ & $34,579.72$ & $38,037.692$ & $10,662.58$ & $14,485.61$ & $21,995.08$ & $26,163.76$ & $28,309.188$ \\
Zhaoqing & 7300.73 & $10,097.2$ & $16,832.37$ & $21,754.4$ & $23,929.84$ & 6750.84 & 7476.65 & $12,163.85$ & $15,728.7$ & $17,160.012$ \\
Shenzhen & $21,577.24$ & $28,665.25$ & $32,380.86$ & $40,741.88$ & $44,653.1$ & $18,200.67$ & $21,188.84$ & $22,806.54$ & $26,727.68$ & $28,812.439$ \\
Dongguan & $14,226.05$ & $22,881.8$ & $35,690.02$ & $42,944.23$ & $46,594.49$ & $12,603.21$ & $21,767.78$ & $25,732.81$ & $31,369.01$ & $33,251.151$ \\
Huizhou & $10,327.78$ & $15,762.77$ & $23,565.24$ & $29,965.02$ & $32,991.487$ & 8945.02 & $12,651.95$ & $19,740.5$ & $22,278.9$ & $24,061.212$ \\
Zhuhai & $15,375.9$ & $18,907.73$ & $25,381.58$ & $32,978.21$ & $36,374.966$ & $12,616.21$ & $14,323.66$ & $20,369.83$ & $24,083.48$ & $26,130.576$ \\
Zhongshan & 11,876 & 17,255 & $25,356.59$ & $31,129.83$ & $34,273.943$ & 9140 & 14,288 & $18,833.13$ & $22,287.55$ & $24,092.842$ \\
Jiangmen & 8942 & 12,903 & $21,152.5$ & $27,016.58$ & $29,772.271$ & - & 9985 & $15,560.79$ & $18,448.45$ & $19,905.878$ \\
\hline
\end{tabular}




\subsection{UEFC and UEFI in PRD Region}

The cities in the PRD region can be divided into three levels, i.e., the first level, the second level and the third level as their UEFI are substantially different. Guangzhou and Shenzhen are two leading cities of the highest UEFI in the region. Foshan and Dongguan are two cities at the second level of the UEFI. Cities at the third level of the UEFI include Zhongshan, Huizhou, Zhuhai, Jiangmen, and Zhaoqing. In the PRD region, Guangzhou and Shenzhen have remarkable advantage over other cities with respect to the UEFI, which obviously shows the core position of Guangzhou and Shenzhen and the subordinate position of the other cities, as shown in Table 8.

Table 8. UEFC and UEFI of the nine cities in PRD in 2005, 2009, 2013.

\begin{tabular}{ccccccc}
\hline \multirow{2}{*}{ Cities } & \multicolumn{3}{c}{ UEFC (Ei) } & \multicolumn{3}{c}{ UEFI (Fi) (100 million yuan) } \\
\cline { 2 - 7 } & $\mathbf{2 0 0 5}$ & $\mathbf{2 0 0 9}$ & $\mathbf{2 0 1 3}$ & $\mathbf{2 0 0 5}$ & $\mathbf{2 0 0 9}$ & $\mathbf{2 0 1 3}$ \\
\hline Guangzhou & 37.07 & 49.71 & 70.80 & 956.58 & 1931.94 & 3363.42 \\
Foshan & 9.84 & 12.02 & 72.20 & 459.54 & 1044.29 & 2905.57 \\
Zhaoqing & 4.46 & 5.30 & 10.18 & 77.57 & 170.48 & 415.14 \\
Shenzhen & 45.99 & 68.88 & 142.19 & 1366.17 & 2544.73 & 4507.75 \\
Dongguan & 4.89 & 6.03 & 126.66 & 538.88 & 1001.27 & 2839.28 \\
Huizhou & 26.56 & 33.06 & 30.44 & 327.22 & 603.22 & 946.78 \\
Zhuhai & 19.14 & 22.05 & 19.64 & 248.40 & 389.42 & 437.72 \\
Zhongshan & 7.34 & 8.48 & 40.75 & 277.08 & 497.56 & 1184.22 \\
Jiangmen & 6.69 & 9.12 & 14.66 & 151.67 & 295.40 & 492.81 \\
\hline
\end{tabular}

The urban economic flow reflects the process of obtaining profits for each city as basic economic sectors conduct external service function. The external income can be expressed by the UEFI, and it contributes to the GDP growth from urban basic economic sectors.

As for the UEFC (Ei) of the nine cities in the PRD, Shenzhen topped the list in 2005 (45.99), 2009 (68.88), and 2013 (142.19). Guangzhou took second place in 2005 (37.07) and 2009 (49.71), but dropped to fourth (70.80), falling behind Dongguan (126.66) and Foshan (72.20) in 2013. Huizhou ranked third in 2005 (26.56) and 2009 (33.06), but dropped to sixth in 2013 (30.44) behind Zhongshan (40.75). Zhuhai was fourth in 2005 (19.14) and 2009 (22.05), but fell to seventh in 2013 (19.64). Jiangmen ranked seventh in 2005 (6.69), sixth in 2009 (9.12), and eighth in 2013 (10.18). Zhaoqing came at the bottom of the list in 2005 (4.46), 2009 (5.30), and 2013 (10.18). Obviously, Dongguan, Foshan, and Zhongshan demonstrated high rates of growth in recent years, as shown in Figure 13. 


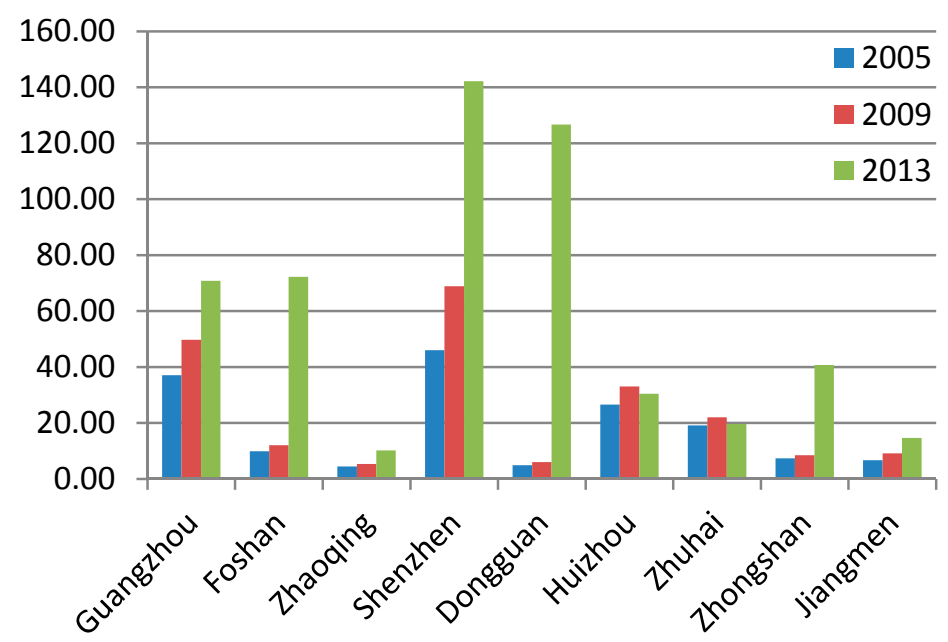

Figure 13. Trends of UEFC of the cities in PRD in 2005, 2009, 2013.

Specifically, Shenzhen enjoyed its remarkable external function capacity advantages in manufacturing, information transmission, computer services and software industry, real estate, and leasing and business services. Guangzhou performed well in transport, storage and postal services, information transmission, computer services, wholesale and retail trade, hotels and catering services, real estate, leasing and business services, scientific research and technical services, water conservancy and environment management, and culture, sports and recreation.

Speaking of the UEFI (Fi) of the nine cities in the PRD, as shown in Figure 14, Shenzhen and Guangzhou took the first two places in 2005, 2009, and 2013. Foshan and Dongguan ranked third and fourth and the gap between them was very small. Zhongshan transcended Huizhou by a slim margin to rank fifth in 2013. Zhuhai lost the seventh position to Jiangmen in 2013. Zhaoqing came last in 2005, 2009, and 2013. In addition, the middle of the PRD region showed the highest UEFI, and the west of the PRD showed the lowest, as shown in Figure 15.

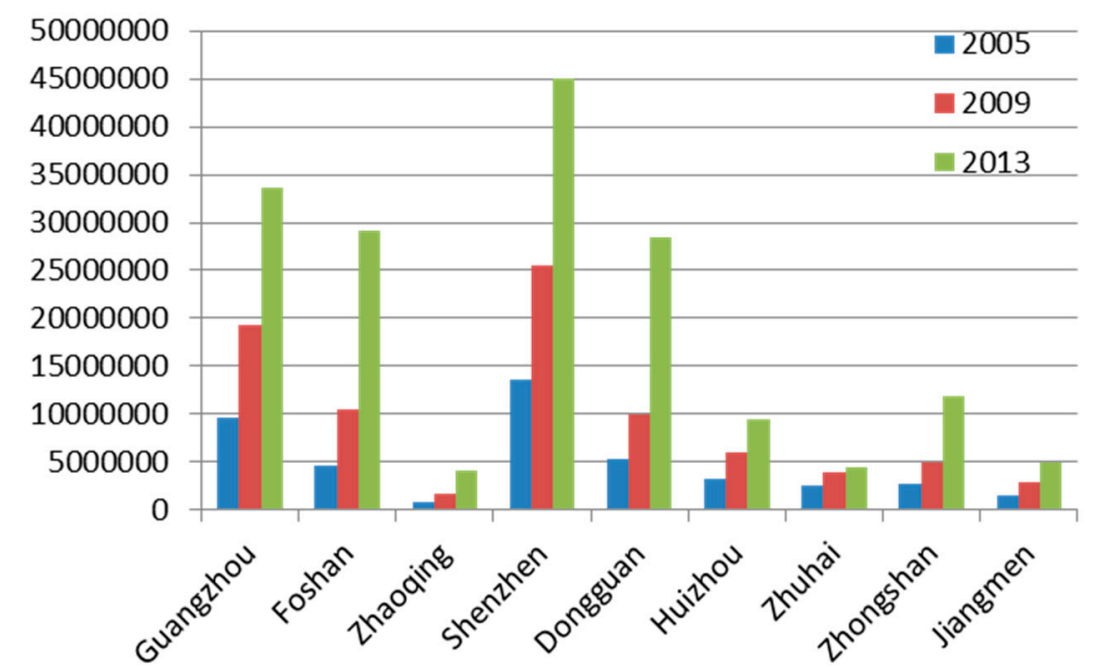

Figure 14. Trends of UEFI of the cities in PRD in 2005, 2009, 2013 (10,000 yuan). 


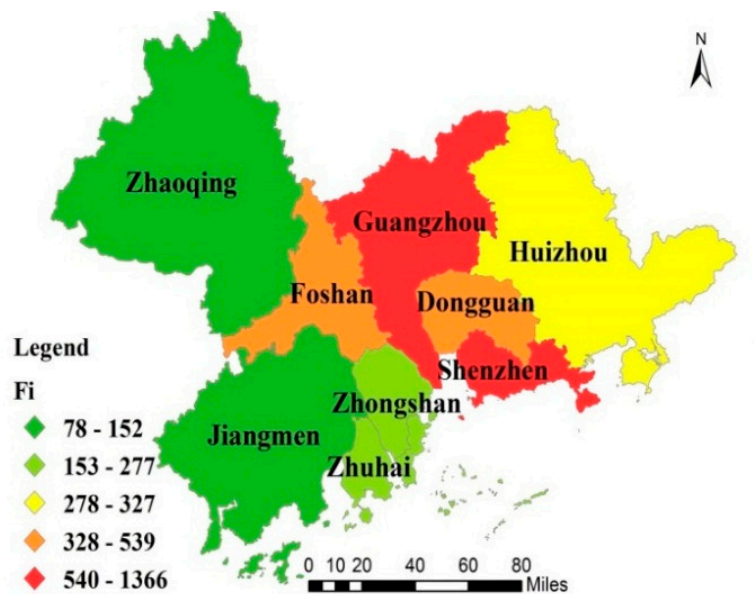

(a)

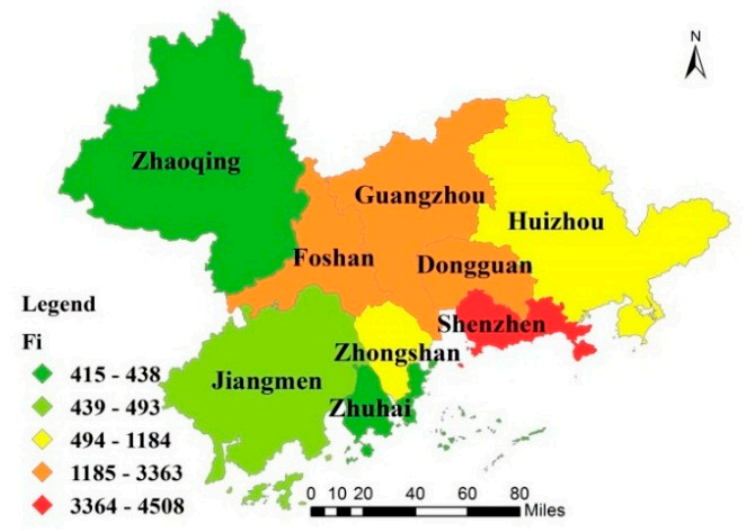

(c)

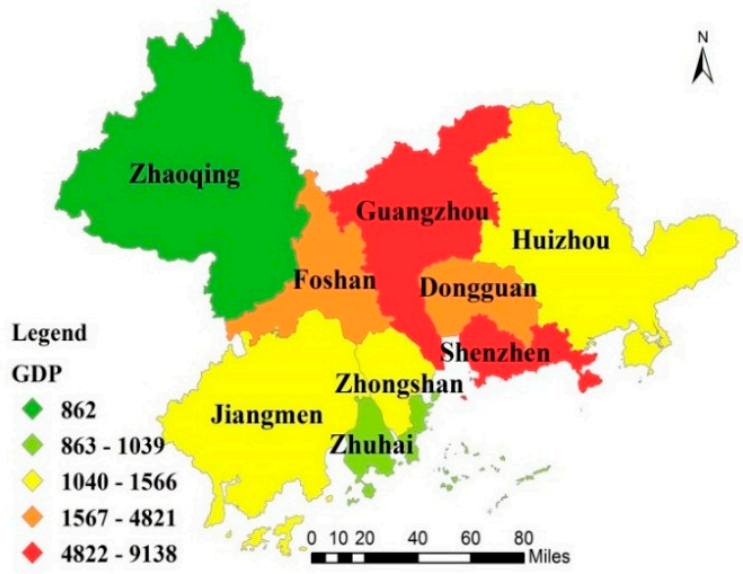

(e)

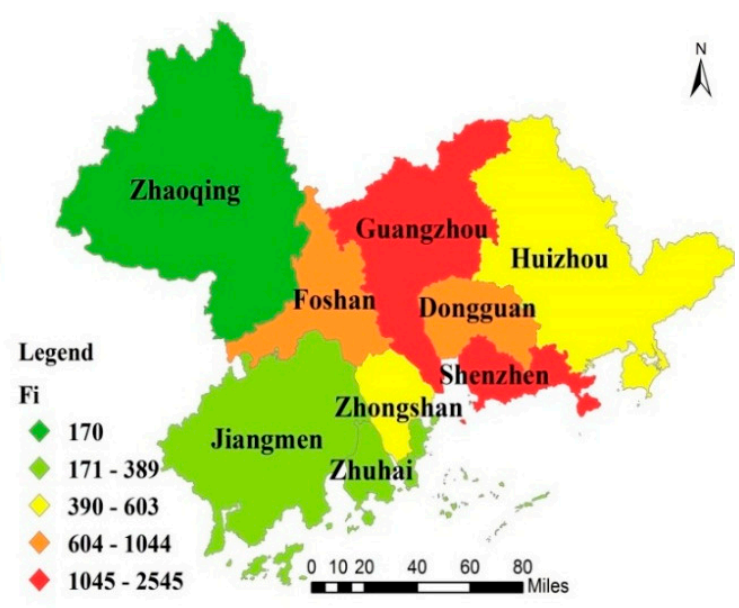

(b)

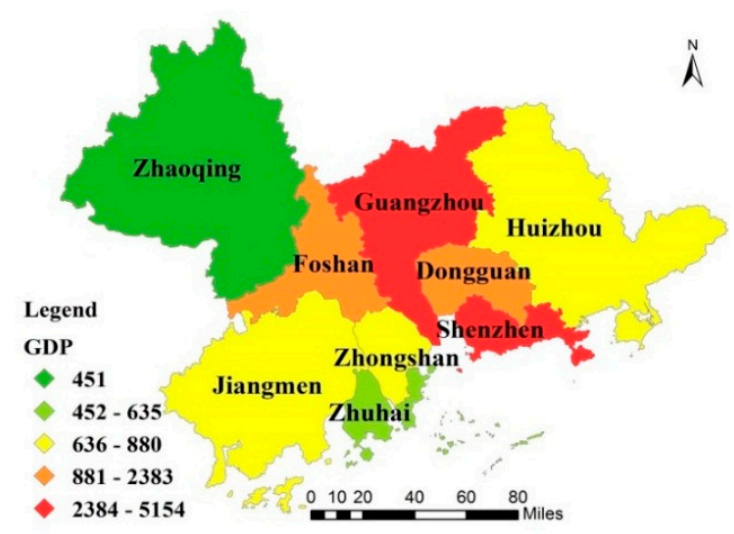

(d)

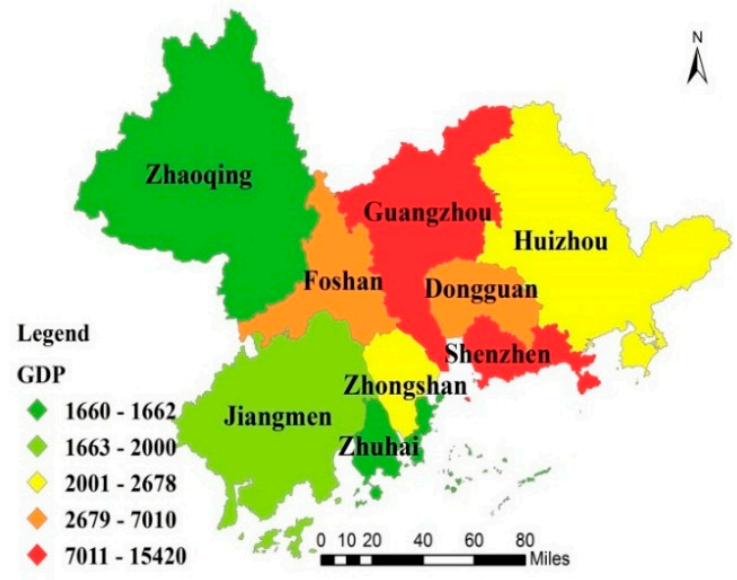

(f)

Figure 15. (a) Spatial distribution of the UEFI (Fi) of all cities in 2005. (100 million yuan); (b) spatial distribution of the UEFI (Fi) of all cities in 2009. (100 million yuan); (c) spatial distribution of the UEFI (Fi) of all cities in 2013. (100 million yuan); (d) spatial distribution of GDP of all cities in 2005. (100 million yuan); (e) spatial distribution of GDP of all cities in 2009. (100 million yuan); and (f) spatial distribution of GDP of all cities in 2013, (100 million yuan). 


\section{Conclusions}

In this paper, the existing significant spatial disparities of urban and regional external economic development in the PRD metropolitan area were analyzed. In addition, we performed the analysis of the LQ, UEFC, and UEFI, discussing the existing typical development bottleneck for major external sectors of the cities, and we proposed the ways to fulfill the development potential of each urban agglomeration in the PRD region. We promoted a more balanced growth in the periphery, through the geographical concentration of economic activities, creating significant scale economies and positive network externalities.

Table 9 showed that all of the LQs of manufacturing were greater than 1 in 2005, 2009, and 2013, which reflected it was apt to form and bring into play the role of the external service function in manufacturing, and the external service capability of manufacturing was strong in the PRD region. There were far fewer cities whose LQs were greater than 1 in wholesale and retail trade sectors, scientific research, technical services sectors, education sectors, culture, sports and recreation, and public administration and social organizations sectors, and the specialization of these sectors was concentrated in a certain city. The numbers of cities with LQs greater than 1 in hotels and catering services sectors, finance sectors, health, and social security and social welfare sectors obviously decreased from 2005 to 2013, which showed that the concentration trend still existed in these sectors' service functions.

Table 9. The number and distribution of cities whose LQ > 1 by sectors in 2005, 2009, 2013.

\begin{tabular}{lccc}
\hline \multirow{2}{*}{ Sectors } & \multicolumn{3}{c}{ Number of Cities Whose LQ > 1 } \\
\cline { 2 - 4 } & $\mathbf{2 0 0 5}$ & $\mathbf{2 0 0 9}$ & $\mathbf{2 0 1 3}$ \\
\hline Manufacturing & 9 & 9 & 9 \\
\hline Transport, storage and postal services & 3 & 2 & 2 \\
\hline Information transmission, computer services & 6 & 4 & 3 \\
\hline Wholesale and retail trade & 1 & 2 & 1 \\
\hline Hotels and catering services & 6 & 6 & 2 \\
\hline Finance & 6 & 5 & 2 \\
\hline Real estate & 3 & 3 & 3 \\
\hline Leasing and business services & 3 & 2 & 2 \\
\hline Scientific research, technical services & 1 & 1 & 1 \\
\hline Water conservancy, environment management & 2 & 1 & 1 \\
\hline Resident services and other services & 1 & 2 & 0 \\
\hline Education & 1 & 2 & 1 \\
\hline Health, social security and social welfare & 6 & 5 & 2 \\
\hline Culture, sports and recreation & 1 & 1 & 1 \\
\hline Public administration and social organizations & 2 & 2 & 1 \\
\hline
\end{tabular}

The UEFI of Guangzhou, Foshan, and Zhaoqing increased remarkably by $102 \%, 127 \%$, and $120 \%$ from 2005 to 2009, respectively, while other cities increased by less than $100 \%$. In addition, The UEFI of Foshan, Zhaoqing, Dongguan, and Zhongshan increased sharply by 178\%, 144\%, 184\%, and 138\% from 2009 to 2013, respectively, while Zhuhai's UEFI increased by only $12 \%$ as the smallest increasing range in the PRD. In 2013, The UEFI of both Foshan and Dongguan accounted for $17 \%$ of the UEFI of the PRD region with a growth of 5\% from 2009, but the proportion of the UEFI of Guangzhou and 
Shenzhen showed a gradual downtrend from $23 \%$ and $30 \%$ in 2009 to $20 \%$ and $26 \%$ in 2013 , respectively. Thus, we came to a conclusion that Foshan took first place in terms of the growth range of the UEFI from 2005 to 2013, while the UEFI of Zhuhai showed the smallest increase. Zhaoqing's UEFI performed a substantial growth from 2005 to 2013, though it continued to account for only $2 \%$ of the total UEFI in the PRD (see Tables S1-S8).

We can put forward the following policy recommendations. In the complicated and changing international context, the development situation is still volatile for all cities and all urban agglomerations in the PRD region in the future of uncertainties. For instance, the flows of all varieties of elements have to be propelled further to overcome difficulties in resource endowment and institutional arrangement. Specifically, the overall strength of technology, market, and talents is insufficient for the sustainable social and economic development in some cities. Cities and regions are badly in need of significant breakthroughs in breaking the administrative barriers.

Urban social and economic integration process concerns regional integration in the PRD region. The construction of intercity rail transit will bring all cities of the PRD into the convenient life circle of one hour around the regional central cities. The resource sharing of public services and facilities will be promoted relying on the development of junction cooperation zones in the urban clusters. [4-7,53]

The same measure that has already been implemented in a given setting can produce a different outcome when implemented in another setting. Additionally, relatively small policy interventions can produce a large impact on regional economic activity [54-57].

In accordance with the government-propelled, market-oriented, and win-win principles, the restrained administrative and institutional obstacles are to be eliminated by the coordinate and cooperative mechanism. It may require coordinated policy interventions to push regional development in the PRD towards a targeted direction.

Guangzhou has to promote high-end element agglomeration, scientific technological innovation, cultural guide and comprehensive service functions. Shenzhen is supposed to play a vital role to set an example as the window of one of the special economic zones and the demonstration plots of independent innovation in China. Moreover, the coordinated layout of regional industries has to be improved in the Guangzhou-Foshan-Zhaoqing (GFZ) urban cluster, the Shenzhen-Dongguan-Huizhou (SDH) urban cluster, and the Zhuhai-Zhongshan-Jiangmen (ZZJ) urban cluster to build the national modern service industries center, the national high-tech industries base, and the world's advanced manufacturing base. According to the current economic basis, local industrial policy orientation and support and prospective development potential of cities and urban clusters, we can build up a more reasonable industrial structure in the PRD region. As for GFZ urban cluster, Foshan has to continue to develop advanced manufacturing and the high-tech industries, in addition to stronger modern service industries, such as finance and logistics industries, collaborating actively with the modern service industries in Guangzhou. Zhaoqing has to carry on the advanced manufacturing supporting industrial transfer from Guangzhou and Foshan on the premise of increasing investment in ecological construction and environmental protection. Meanwhile, Zhaoqing has to vigorously develop tourism with its superior natural endowment. As for the SDH urban cluster, Dongguan has to improve its comprehensive external service capabilities to meet the requirements of local people and a large immigrant population, most of whom work in the manufacturing sectors. To build the eastern Pearl River estuary economic corridor with strong external service capabilities and overall economic strength is the breakthrough point for the SDH urban cluster. As for 
the ZZJ urban cluster, boosting the industrial concentration on the western coast of Peal River estuary is an initial accomplishment that opens the way for further developments. Cities like Zhuhai and Jiangmen in this urban cluster showed a relatively slower increase in the UEFI, whose comprehensive urban external service capabilities should be improved. Specifically, Zhuhai has to take advantage of the historical opportunity to vigorously develop the modern service industries, such as finance, business and exhibition, and logistics, for the Hengqin New Area of Zhuhai has formally become one of the Pilot Free Trade Zones in Guangdong since 23 April 2015. Zhongshan and Jiangmen are supposed to build the key development area of advanced manufacturing industry and strive to develop the modern service industry. Meanwhile, potential ecological and environmental problems caused by the process of economic growth cannot be neglected. All cities in the PRD region have to draw up and carry out regional coordinated planning of ecological construction and environmental protection with respect to water, air, soil, and heavy metal pollution. The joint control and prevention mechanism of environmental contamination is supposed to be strengthened further to consolidate ecological construction and environmental protection achievements. More investment should be made in environmental protection infrastructures to better meet the demands of the disposal of contaminants and wastes, and all kinds of threats should be contained from the headstream by the construction of a regional joint monitoring network and rigorous supervision system.

It is important to build a unified and open infrastructure, factor market, technological and intelligent supporting systems and industrial cooperation platforms to promote the transition from a simple competition to a cooperation-competition mode, from an urban economic mode to a regional economic mode. Transportation and communications infrastructure must be modernized so they can have a positive impact on industrial growth [58]. Improved transport and communications infrastructure construction can better fulfill the free mobility of population flow, goods flow, fund flow, and information flow in the PRD region. In further research, longer periods would be selected to be investigated to further analyze the spatial and temporal evolution of urban external service capabilities.

\section{Acknowledgments}

Thanks to Municipal Bureau of Personnel in Guangzhou, Foshan, Zhaoqing, Shenzhen, Dongguan, Huizhou, Zhuhai, Zhongshan and Jiangmen for offering necessary related materials on local employment situation.

\section{Author Contributions}

This paper represents a result of teamwork. Meng Wang performed the data analysis and wrote the manuscript; Yaoqiu Kuang added significant ideas to the writing of this paper; Ningsheng Huang guided the overall analysis with constructive discussions. All authors have read and approved the final manuscript.

\section{Conflicts of Interest}

The authors declare no conflict of interest. 


\section{References}

1. Glaeser, E.; Gottlieb, J. Urban resurgence and the consumer city. Urban Stud. 2006, 43, 1275-1299.

2. Mayer, M. The onward sweep of social capital: Causes and consequences for understanding cities, communities and urban movements. Int. J. Urban Reg. Res. 2003, 27, 110-132.

3. Taylor, P.J. Leading world cities: empirical evaluations of urban nodes in multiple networks. Urban Stud. 2005, 42, 1593-1608.

4. Lin, X.B.; Ma, X.G.; Chao, H.; Li, G.C. Research on spatial organizational successions of the PRD mega-region by global principal component analysis method. Hum. Geogr. 2014, 29, 59-65.

5. Mei, Z.X.; Xu, S.J.; Ouyang, J.; Shi, C. The spatio-temporal evolvement of spatial interaction among cities of Zhujiang River Delta in recent 20 years. Sci. Geogr. Sin. 2012, 32, 694-700.

6. Xu, X.Q.; Chen, Y.H. Spatial-temporal changes of urban competitiveness in urban cluster of Pearl River Delta. Sci. Geogr. Sin. 2006, 26, 257-265.

7. Yin, L.S.; Feng, B.Y. The spatial evolution of the Pearl River Delta city region. Econ. Geogr. 2012, $32,63-70$.

8. Brenner, T.; Weigelt, N. The evolution of industrial clusters: Simulating spatial dynamics. Adv. Complex Syst. 2001, 4, 127-147.

9. Duranton, G.; Storper, M. Rising trade costs? Agglomeration and trade with endogenous transaction costs. Can. J. Econ. 2008, 41, 292-319.

10. Storper, M.; Venables, A.J. Buzz: Face-to-face contact and the urban economy. J. Econ. Geogr. 2004, 4, 351-370.

11. Scott, A.J.; Storper, M. The Nature of Cities: The Scope and Limits of Urban Theory. Int. J. Urban Reg. Res. 2015, 39, 1-15.

12. Henderson, J.V. Cities and Development. J. Reg. Sci. 2010, 50, 515-540.

13. McFarlane, C. The comparative city: knowledge, learning, urbanism. Int. J. Urban Reg. Res. 2010, 34, 725-742.

14. Robinson, J. Cities in a world of cities: the comparative gesture. Int. J. Urban Reg. Res. 2011, 35, 1-23.

15. Shearmur, R.; Alvergne, C. Intra metropolitan patterns of high-order business service location: A comparative study of seventeen sectors in Ile-de-France. Urban Stud. 2002, 39, 1143-1163.

16. Lundmark, M. Computer Services in Sweden: Markets, labour qualifications and patterns of location. Geogr. Ann. Ser. B 1995, 77, 125-139.

17. Pandit, N.R.; Cook, G.A.S.; Swann, G.M.P. A comparison of clustering dynamics in the British broadcasting and financial services industries. Int. J. Econ. Bus. 2002, 9, 195-224.

18. Sealte, G.H. Changes in producer services location, Sydney: Globalization, technology and labor. Asia Pac. Viewp. 1998, 39, 237-255.

19. Jaakko, S. Regional Externalities in the Dynamic System of Three Regions. Pap. Reg. Sci. 2006, $85,421-442$.

20. Neffke, F.; Henning, M. How Do Regions Diversify over Time? Industry Relatedness and the Development of New Growth Paths in Regions. Econ. Geogr. 2011, 87, 237-265.

21. Márguez, M.A.; Hewings, G.J.D. Geographical Competition between Regional Economies: The Case of Spain. Ann. Reg. Sci. 2003, 37, 559-580. 
22. Wu, F.L.; Fang, C.L.; Zhao, Y.P. The Progresses of Urban Industrial Agglomeration Dynamic Mechanism and Patterns. Prog. Geogr. 2010, 29, 1201-1208.

23. Kirn, T.J. Growth and change in the service sector of the U. S.: A spatial perspective. Ann. Assoc. Am. Geogr. 1987, 77, 353-372.

24. Allen, J. Services and the UK space economy: Regionalization and economic dislocation. Trans. Inst. Br. Geogr. 1992, 17, 292-305.

25. Coe, N.M.; Townsend, A.R. Debunking the myth of localized agglomerations: The development of a regionalized service economy in South-East England. Trans. Inst. Br. Geogr. 1998, 23, 385-404.

26. Grover, D. The South East of England: Global region without a global city? Reg. Sci. Policy Pract. 2012, 4, 65-81.

27. Krapohl, S.; Meissner, K.L.; Muntschick, J. Regional Powers as Leaders or Rambos? The Ambivalent Behaviour of Brazil and South Africa in Regional Economic Integration. J. Common Mark. Stud. 2014, 52, 879-895.

28. Bishop, P.; Gripaios, P. Spatial externalities, relatedness and sector employment growth in Great Britain. Reg. Stud. 2010, 44, 443-454.

29. Barrios, S.; Bertinelli, L.; Stroble, E.; Teixeira, A.C. The dynamics of agglomeration: Evidence from Ireland and Portugal. J. Urban Econ. 2005, 57, 170-188.

30. Deutz, P.; Ioppolo, G. From Theory to Practice: Enhancing the Potential Policy Impact of Industrial Ecology. Sustainability 2015, 7, 2259-2273.

31. Ioppolo, G.; Heijungs, R.; Cucurachi, S.; Salomone, R.; Kleijn, R. Urban Metabolism: Many open questions for future answers. In Pathways to Environmental Sustainability: Methodologies and Experiences; Salomone, R., Saija, G., Eds.; Springer International Publishing AG: Dordrecht, The Netherlands, 2014; pp. 23-32.

32. Kennedy, C.A.; Pincetl, S.; Bunje, P. The study of urban metabolism and its applications to urban planning and design. Environ. Pollut. 2011, 159, 1965-1973.

33. Ioppolo, G.; Cucurachi, S.; Salomone, R.; Saija, G.; Ciraolo, L. Industrial Ecology and Environmental Lean Management: Lights and Shadows. Sustainability 2014, 6, 6362-6376.

34. Van Berkel, R.; Fujita, T.; Hasimoto, S.; Fjuii, M. Quantitative assessment of urban and industrial symbiosis in Kawasaki Japan. Environ. Sci. Technol. 2009, 43, 1271-1281.

35. Zhang, W.Q. Study on Urban Development in Longhai-Lanxin Zone; China Building Industry Publishing House: Beijing, China, 1994; pp. 299-315.

36. Wang, S.; Song, Y.; Feng, Z.; Jiang, L. Pattern and Progress of Large Urban Agglomerations and Urban Flows Intensity in Northeast China. Sci. Geogr. Sin. 2011, 31, 287-294.

37. Liu, J.; Gao, S. The Research of Beijing-Tianjin-Hebei Urban Agglomerations' Spatial Connection Based on Urban Relation Intensity and Urban Flow. Areal Res. Dev. 2013, 32, 57-61.

38. Zhang, L.; Gao, S. Analysis on Spatial Connection in Beijing-Tianjin-Hebei Metropolitan Region from the Perspective of Polycentricity. Urban Dev. Stud. 2014, 21, 49-54.

39. Zhu, H.; Jiang, Z. The Inherent Functional Relations of Mid-Zhejiang Urban Cluster Based on the Urban flow and its Policy Response. Urban Dev. Stud. 2008, 15, 16-20.

40. Liu, H.; Yang, Q.; Yang, B.; Feng, J. Study on Inner Mongolia City Development from Perspective of Urban Flow. Resour. Dev. Mark. 2014, 30, 1239-1242. 
41. Ke, W.; Lu, Y.; Yu, Z.; Wang, H.; Chen, W.; Ma, Y. Spatio-temporal Evolution Patterns of External Service Capabilities of Chinese Central Cities Based on Urban Flow Intensity. Sci. Geogr. Sin. 2014, $34,1305-1312$.

42. Dong, H.; Zhang, Y.; Shi, P. Analysis and its Policy Response on the Intensity of Urban Flow in the Lanzhou-Xining-Yinchuan Urban Corridor. J. Arid Land Resour. Environ. 2011, 25, 27-32.

43. Han, Z.; Guo, J.; Yang, D. The Spatial Relationship between Coastal Economic Belt in Liaoning Province and its Hinterland and Interaction Strategy. Econ. Geogr. 2011, 31, 741-747.

44. Statistics Bureau of Guangdong Province. Guangdong Statistical Yearbook 2014. Available online: http://www.gdstats.gov.cn/tjsj/gdtjnj/ (accessed on 10 April 2015).

45. Mora, T.; Moreno, R. Specialization changes in European regions: the role played by externalities across regions. J. Geogr. Syst. 2010, 12, 311-334.

46. Editorial Board. China City Statistical Yearbook 2014; China Statistics Press: Beijing, China, 2015; pp. 1-477.

47. Gomez-Herrera, E.; Martens, B.; Turlea, G. The Drivers and Impediments for Cross-Border E-Commerce in the EU. Inf. Econ. Policy 2014, 28, 83-96.

48. Erdal, A.; Burcu, K.S. The Relationship between Globalization and E-Commerce: Turkish Case. Procedia Soc. Behav. Sci. 2014, 150, 1267-1276.

49. Statistics Bureau of Guangdong Province. Post and Telecommunications Performed Positive Growth Trend in Guangdong in the first half of 2015. Available online: http://www.gdstats.gov.cn/tjzl/tjkx/201507/t20150722_310004.html (accessed on 22 July 2015).

50. Dongguan Municipal Postal Administration. Running Condition of the Postal Industry in Dongguan in May, 2015. Available online: http://gddg.spb.gov.cn/xytj_7842/tjxx/201506/t20150616_ 515414.html (accessed on 16 June 2015).

51. Zhongshan Municipal Postal Administration. Running Condition of the Postal Industry in Zhongshan in May, 2015. Available online: http://gdzs.spb.gov.cn/xytj_7938/tjxx/201506/ t20150619_518339.html (accessed on 19 June 2015).

52. Jiangmen Municipal Postal Administration. Running Condition of the Postal Industry in Jiangmen in May, 2015. Available online: http://gdjm.spb.gov.cn/xytj_7970/tjxx/201506/t20150616_ 515442.html (accessed on 16 June 2015).

53. Li, X.; Wen, F.H.; Xu, X.Q. Urban size structure and fractal characteristics of PRD since implementing the reform\& open policy. Trop. Geogr. 2007, 27, 239-244.

54. Tsekeris, T.; Vogiatzoglou, K. Public infrastructure investments and regional specialization: empirical evidence from Greece. Reg. Sci. Policy Pract. 2014, 6, 265-289.

55. Bickenbach, F.; Bode, E. Disproportionality measures of concentration, specialization, and localization. Int. Reg. Sci. Rev. 2008, 31, 359-388.

56. Chatman, D.G.; Noland, R.B. Do public transport improvements increase agglomeration economies? A review of literature and an agenda for research. Transp. Rev. 2011, 31, 725-742.

57. Hanson, G.H. Market potential, increasing returns and geographic concentration. J. Int. Econ. 2005, 67, 1-24. 
58. Gregory, B.; Vicente, G. Regional industrial growth in Mexico: Do human capital and infrastructure matter? J. Policy Model. 2013, 35, 228-242.

(C) 2015 by the authors; licensee MDPI, Basel, Switzerland. This article is an open access article distributed under the terms and conditions of the Creative Commons Attribution license (http://creativecommons.org/licenses/by/4.0/). 